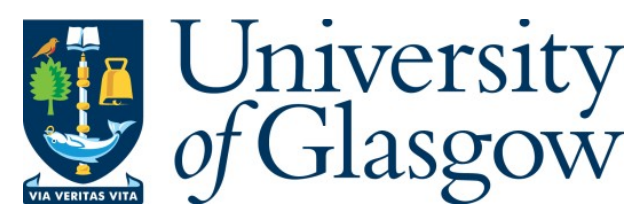

Xiao, Z. and Harrison, P. (2021) Design of buckling and damage resistant steered fibre composite laminates using trellis shear kinematics. Composite Structures, 260, 113526.

(doi: 10.1016/j.compstruct.2020.113526)

This is the Author Accepted Manuscript.

There may be differences between this version and the published version. You are advised to consult the publisher's version if you wish to cite from it.

https://eprints.gla.ac.uk/233353/

Deposited on: 4 February 2021

Enlighten - Research publications by members of the University of Glasgow http://eprints.gla.ac.uk 


\section{Design of buckling and damage resistant steered fibre composite laminates using trellis shear kinematics}

Zhaofei Xiao ${ }^{a, b}$ and Philip Harrison ${ }^{b}$

${ }^{a}$ ASTUTE2020, College of Engineering, Swansea University, Swansea, UK, SA1 8EN

b James Watt School of Engineering, University of Glasgow, Glasgow, UK, G12 8QQ

Key words: A. Variable Stiffness Laminates; B. Buckling; B. Failure; E. Fabric Steering.

\section{Abstract}

A Matlab ${ }^{\circledR}$-based numerical tool, 'SteerFab', is developed to predict steered fibre patterns and to analyse the mechanical properties of the resulting variable stiffness panels using the finite element software, Abaqus ${ }^{\mathrm{TM}}$. Based on trellis shear kinematics [1], both the steered fibre pattern and the shape of the corresponding initial undeformed sheet can be created by SteerFab. Two types of rectangular plates measuring $300 \mathrm{~mm} \times 400 \mathrm{~mm}$ are considered in this numerical study, one with and one without a $90 \mathrm{~mm}$ diameter central hole. For the plate with a hole, the finite element analysis predicts that the optimised steered-fibre pattern achieves similar improvements for both a carbon-epoxy composite ( $6 \%)$ and a glass-epoxy composite $(\sim 7 \%)$ in terms of buckling resistance load, while failure load is increased by about $5 \%$ for a carbon-epoxy composite and $10 \%$ for a glass-epoxy composite compared to the best performing equivalent straight-fibre laminates. 


\section{Introduction}

In order to achieve extreme lightweight design and improve fuel efficiency, manufacturers in aerospace and automotive industries increasingly exploit composite materials due to their high specific and tailorable mechanical properties. Typically, for structures subject to multiple loading directions, designers make use of multi-axial straight fibre laminates, often in the form of quasi-isotropic layups. Recently, various researchers have investigated the potential of continuously changing, or steered, fibre paths across laminates to manufacture Variable Stiffness Panels (VSPs) [2-4]. Table 1 summarises the improvement of VSPs in buckling load in previous studies [5-12]. VSPs offer better buckling resistance than conventional straight-fibre laminates of the same weight and the improvement percentage ranges from $10 \%$ to $189 \%$ subject to steered-fibre paths, layup sequences, benchmarks (straight-fibre composites), aspect ratios of the panels (Length/Width) and boundary conditions. Typically, finite element analysis (FEA) is used to conduct numerical optimisation of buckling load for VSPs [5-12]. This process can require significant computational resource, especially when a large number of elements is needed to achieve high prediction accuracy. However, computational efficiency can be significantly improved by using isogeometric analysis (IGA), a method recently proposed in [13-15]. The technique ensures continuity of the changing fibre angle across the whole panel. The high improvement of $189 \%$ was achieved in [10] via optimisation of laminate parameters, but the corresponding fibre orientation and layup sequence were not reported. Although it is possible to convert laminate parameters into curvilinear fibre path and layup sequence $[16,17]$, it is not clear whether the optimum laminate parameter in [10] is achievable and can be manufactured in reality. According to Table 1 , the improvement of VSPs in buckling load are generally more significant (over 50\%) when the edges of the VSPS 
are moderately constrained (i.e. only simply supported) [6, 10-12]. However, Marouene et al. [12] reported it was difficult to replicate this boundary condition in the laboratory. Furthermore, the steered fibre paths in VSPs can reduce the negative influence of a central hole on the structural performance of panels, by relocating failure initiation away from the hole [9]. These performance enhancements have led to consideration of VSPs for T-shaped stiffened skin and fuselage panels in aircraft $[18,19]$.

VSPs are normally manufactured using Automated Fibre Placement machines. However, because of the resistance to in-plane bending deformation of fibre tows during layup, three types of defects are typically induced in VSPs: (a) tow overlaps or (b) inter-tow gaps and (c) tow-scale wrinkles [20-23]. Some researchers [24-26] have developed detailed finite element models of VSPs containing these defects (e.g. tow gaps and overlapping) in order to understand their effects on the mechanical behaviour of VSPs. Others have focused on enhancing the standard AFP production process in order to eliminate these defects altogether, by developing a technique known as continuous tow shearing technology [21, 22]. The main aim of the current paper is to investigate the potential of an entirely different production method to the use of AFP, namely, fibre steering via in-plane trellis shear of biaxial engineering fabric or cross-ply prepreg sheets. The practical problem of how to achieve such deformation in real materials will be addressed in a subsequent investigation. Here the focus is on whether advanced composite structures containing steered fibre paths, produced via ideal pin-jointed net kinematics (i.e. involving the kinematic constraints of fibre inextensibility, free rotation of the two sets of initially orthogonal fibre paths and perfect pinning at fibre cross-over points), can in principle confer any structural advantage in comparison with purely straight fibre laminates. If this turns out to be the case, then the implication is that VSPs might be manufactured by manipulating standard biaxial fabrics and cross-ply prepregs, potentially 
pointing to alternative and possibly advantageous production technologies. Additionally, if this process could be automated, it could lead to lower costs as the process begins with large sheets of inexpensive engineering fabric that can be steered, in contrast to AFP which is effectively a relatively slow additive manufacturing process. However, the fibre paths produced under the more severe constraints of pin-jointed net kinematics are likely to be different (more limited) than those generated by standard AFP and continuous tow shearing AFP technology. For example, in this newly proposed manufacturing process, the achievable variation range of fibre orientation is limited by the maximum shear angle that can be reached in a fabric or cross-ply prepreg without inducing wrinkles. Consequently, the present paper aims to examine this possibility through purely numerical investigation. To this end, a design tool, SteerFab [27], able to generate 2-D steered fibre patterns based on predictions involving pin-jointed net kinematics, has been developed. The code is a development of a pre-existing Matlab ${ }^{\circledR}$ code, VariFab, the implementation of which was detailed in Section 4.1 of [1]. For clarity, the original algorithm is also summarised in Section 2.2 of this paper. New developments to the algorithm, required to generate controllable steered fibre paths, are also described.

The remaining sections of this paper are structured as follows; first the working process and operational features of SteerFab are outlined before presenting outputs from the code. The optimum steered fibre path is found via a parameter study examining the buckling resistance of a range of VSPs generated using the code (these initial results were briefly presented in [27]). The investigation then considers the post-buckling performance of the best performing VSP identified in the preceding buckling investigation. Finally, conclusions of the investigations are presented. 


\section{Development of SteerFab}

SteerFab is designed to automatically generate laminate layups containing both straight and steered-fibre paths (referred to in this paper as a 'hybrid steered/straight fibre laminates') and to subsequently export this information in the correct format for mechanical analysis in the commercial finite element software, Abaqus ${ }^{\mathrm{TM}}$ [28]. The mechanical properties of laminates incorporating these hybrid steered/straight fibre paths are then analysed. As mentioned, the code is developed froma preceding kinematic code, VariFab [1]. Whereas the latter applies relatively small perturbations to predict statistically representative variability of fibre orientation across a biaxial fabric, SteerFab is designed to create purposeful steeredfibre patterns. Hence, the function controlling the shape of the fibre paths is designed to achieve intentional and beneficial shear deformations (within the fabric's forming limits) that can be directly and conveniently controlled by the user.

\subsection{Process Flow}

The process flow contains four steps described below and illustrated in Figure $1(A)$ to(F).

- Step 1: Create steered fibre paths (see Figure 1B) using pin-jointed net kinematics [1, 29] (details of the algorithm are provided in Section 2.2). The original perimeter shape of the unsteered material can be recovered from the steered shape, as shown in Figure $1 \mathrm{~A}$.

- Step 2: A finite element model (described in Section 2.2) is generated in Abaqus $^{\mathrm{TM}}$ (see Figure 1C), the coordinates of each element of the finite element mesh (see Figure 1D) are read and formatted (by listing the element number and coordinates of the nodes in a format suitable for an Abaqus ${ }^{T M}$ input file) ready for post-processing in Step 3, 
- Step 3: Using the element information (element number and nodal co-ordinates) an algorithm, originally developed in [30], is used to map the fibre angle and ply thickness from the steered fibre paths created in Step 1 (see Figure 1B) to each element in the FE model using bi-linear interpolation,

- Step 4: Structural simulation of the straight/steered fibre laminate (see Figure 1F) is performed using the prepared FE model from Step 3. The structural performance of the resulting laminate is predicted, in terms of both its buckling and damage resistance.

Figure 2 shows the flow chart of the code, which can repeatedly run through Steps 1 to 4 until all the steered-fibre patterns controlled by the user-defined control functions are generated and analysed to determine the optimal mechanical performance of the laminate, when subject to specified loading conditions. An optional layup hybridisation function allows the user to create either straight, steered or hybrid steered/straight fibre laminates, as shown in Figure 3. The fibre angle and ply thickness across the laminate is superposed within the FE model. Users can define both the fibre orientations of the straight-fibre plies and the number of plies within the laminate. Users can either manually input the stacking sequence of the plies or alternatively, automatically generate all possible stacking sequences, analyse their performance, and ultimately determine the optimum layup.

\subsection{Implementation of Kinematics}

The mesh generation algorithm used here is the same as that used in VariFab [1]. For clarity, a short description of the algorithm is repeated here using the same symbols as those used in [1]. Variables input by the user include the side length of the elements, $\Lambda$, (see Figure $4 A$ ), and the size and shape of the perimeter of the steered fibre mesh. After the mesh is generated 
by the algorithm, described in detail in the following text, it can be cropped in various shapes. For example, to create Figure $1 \mathrm{~B}$, a rectangular mesh has been specified; circular and polygonal perimeter shapes can also be generated. Due to the fibre inextensibility constraint, stretching/contraction of elements along the horizontal centreline of the mesh fully determines the fibre directions across the rest of the mesh, i.e. once the nodal positions along the centreline are determined, the positions of all other nodes in the mesh can be calculated. Figure 4B shows how coordinates of nodes on the outermost upper left edge (indicated by filled red points in Figure 4) are determined using Equations (1) and (2):

$X=\left[\begin{array}{c}\left(-2 \sum_{i=1}^{n} a_{n}(i)\right) \\ \left(-2 \sum_{i=1}^{n} a_{n}(i)+a_{n}(n)\right) \\ \left(-2 \sum_{i=1}^{n} a_{n}(i)+a_{n}(n)\right)+a_{n}(n-1) \\ \vdots \\ \operatorname{row}(n)+a_{n}(1) \\ \operatorname{row}(2) \\ \operatorname{row}(3) \\ \vdots \\ \operatorname{row}(n+2)+a_{n}(2) \\ \vdots \\ \operatorname{row}(2 n+1) \\ \operatorname{row}(n+2) \\ \operatorname{row}(n+3) \\ \vdots \\ \operatorname{row}(2 n+1)\end{array}\right.$

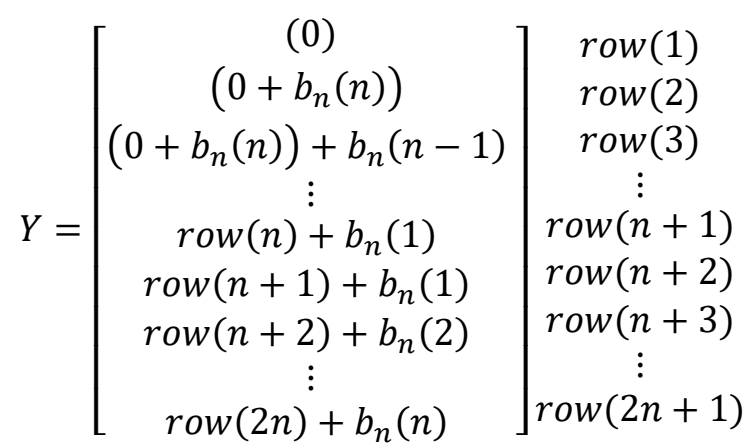

where $X$ and $Y$ are arrays that are added to the nodal position matrix. $n$ is the number of elements from the centre of the blank to either the right, left, top or bottom edge of the mesh, $i$ is the node number when counting outwards from the centre of the blank towards the outer edge of the mesh along the vertical or horizontal mesh centerlines, $a_{\mathrm{n}}$ is an array containing the half lengths of the horizontal diagonal element lengths, while $b_{\mathrm{n}}$ is an array containing the 
half lengths of the vertical diagonal element lengths. The relationship between $a_{\mathrm{n}}$ and $b_{\mathrm{n}}$ is determined by Equation (3):

$b_{n}=\sqrt{\Lambda^{2}-a_{n}^{2}}$

After the coordinates of nodes on the outermost upper left edge are determined, the coordinates are shifted right by $a_{\mathrm{n}}(\mathrm{n})$ and shifted down by $b_{\mathrm{n}}(\mathrm{n})$ to create an inner layer of the nodes. Then the coordinates of these new nodes are shifted right by $a_{\mathrm{n}}(\mathrm{n}-1)$ and shifted down by $b_{n}(n-1)$ to create a new inner layer of the nodes. This process continues to create all the nodes of the steered mesh.

Hence the array, $a_{\mathrm{n}}$, can control the generated mesh pattern and was used together with other factors controlling off-axis deformation in [1] to introduce realistic variability in the resulting meshes. $a_{\mathrm{n}}[1]$ is controlled using a mathematical function, $\chi=\mathrm{f}(\theta)$, where $\theta$ is the shear angle of the elements of the mesh along the horizontal generation line. In this investigation, the relationship between $a_{\mathrm{n}}$ and $\chi$ is expressed by Equation (4), a trigonometric function.

$a_{n}(n)=\Lambda \sin [90-\chi(n)]$

The function $\chi$ can take an arbitrary form to create a wide range of steered patterns. Figure 5 demonstrates three distinctly different steered patterns created by three alternative functions for $\chi$. These functions are intentionally selected to create different variations in the shear angle along the horizontal mid-height axis, from the centre to the vertical edge of the pattern. They show the capability to explore the mechanical properties of a wide variety of steered-fibre patterns. Figure $5 \mathrm{~A}$ uses a parabolic function $\chi=73-6000 \times(\mathrm{t}-0.07)^{2}$, Figure 5B uses a third-order polynomial function $\chi=1.6+1523 t-12947 t^{2}+42272 t^{3}$, 
and Figure $5 \mathrm{C}$ uses a trigonometric function $\chi=38.5-20 \cos (52 t)$. Many other functions could be chosen.

In this investigation $\chi$ is given by Equation (5), simply because this equation can create steered-fibre patterns similar to those created using AFP in [7] in a convenient format. The motivation is to demonstrate that VSPs made using Fabric Steering Technology are comparable with those made using AFP.

$\chi=45-\mathrm{t}^{2} \times \theta_{\max } / 0.045$

where $t$ is the distance from the centre of the steered pattern to a given point along the horizontal mid-height axis and $\theta_{\max }$ is the maximum shear angle at the end of the horizontal mid-height axis of the steered fabric, as shown in Figure 6 (note that $\theta_{\max }$ is not necessarily the highest shear angle generated across the entire sheet). In the present work, the values of $\theta_{\max }$ used in the simulations is $\left[10^{\circ} ; 25^{\circ} ; 30^{\circ} ; 35^{\circ} ; 40^{\circ} ; 45^{\circ}\right]$. The upper limit of $\theta_{\max }$ is set here at $45^{\circ}$ which makes the highest shear angle of the entire pattern about $49^{\circ}$, this is a conservative value that should avoid potential manufacturing issues when aiming to form the steered sheet. In [31], the measured wrinkle onset shear angles of both glass and carbon-fibre fabrics were greater than $50^{\circ}$. Note that the practical manufacture method will be discussed in a future investigation, here we simply assume that manufacture is possible.

As mentioned in Section 2.1, the tow angle and thickness of the generated steered patterns needs to be mapped to a finite-element model for stress analysis. Each steered pattern provides orientation information for two distinct steered fibre plies, denoted here as ( \pm SFP). The approximation is therefore closer to the behaviour of a steered non-crimp fabric than a woven fabric, as effects of tow undulation due to crimp are neglected in the current structural analysis. While it may be possible to apply a detailed meso-scale model for woven steered 
fabric composites using tow-level architectures (e.g. tow spacing and crimps), the complexity and computational cost of this approach is very high, especially if the effects of shear on the meso-structure are considered. Thus, here we aim simply to understand whether the fibre steering is beneficial without considering the added complexity of a woven fabric architecture. In order to map thickness, the material is treated as incompressible with a constant fibre volume fraction (a reasonable approximation for a cross-ply prepreg composite) [32]. Hence, the local thickness of the steered sheet, $T$, is calculated as:

$$
\mathrm{T}=\mathrm{T}_{0} / \cos \theta
$$

where $T_{0}$ is the thickness of the undeformed sheet and $\theta$ is the shear angle.

\section{Method of investigating the buckling behaviour of steered -fibre laminates}

The method of investigating the buckling behaviour of VSP's is summarised here and follows two stages: Stage 1 is a screening investigation, designed to understand the influence of stacking sequence, geometry and material behaviour on buckling performance. Numerous straight and steered fibre laminates are generated by SteerFab and their buckling resistance loads are predicted in Abaqus ${ }^{\mathrm{TM}}$. Individual ply properties, obtained from [9] and [33] for simulations, are listed in Table 2. Table 3 lists the nine types of laminate considered in this investigation (see the layup hybridization function described in Section 2.1) for structural analysis. The selection of laminates is inspired by previous studies on VSPs $[7,9]$. The steered patterns of the SFP plies are created using Equation (5) and the side length of the kinematic

elements $(\Lambda)$ is $7 \mathrm{~mm}$. A shorter kinematic element length $(\Lambda=3 \mathrm{~mm})$ was also tested, however, the subsequent accuracy when mapping fibre orientations and ply thickness onto 
shell elements of the finite element models unaffected. Hence, the kinematic element length of $7 \mathrm{~mm}$ was selected to improve computation speed. The steered-fibre pattern is specified as a rectangular shape with a size of $300 \times 400 \mathrm{~mm}$, matching the geometry of the finite element model created in Abaqus ${ }^{\mathrm{TM}}$. In Stage 2, the best performing hybrid steered/straight fibre laminates and straight fibre laminates determined in Stage 1, are selected for further non-linear post-buckling simulations where the failure mechanics of the laminates are predicted.

The finite element models generated in Abaqus ${ }^{\mathrm{TM}}$ employ thin S4R shell elements with 'composite' section properties. The stiffness of the shell elements is predicted using classical laminate theory. The buckling performance of two $300 \times 400 \mathrm{~mm}$ VSPs were evaluated, one with and one without a $90 \mathrm{~mm}$ diameter central hole. Figure 7 shows the corresponding FE models comprised of 4800 elements, each element measuring about $5 \times 5 \mathrm{~mm}$. A mesh sensitivity study using a finer mesh comprised of 19,200 elements (each measuring about $2.5 \times 2.5 \mathrm{~mm}$ ) revealed a change of just $0.6 \%$ in the predicted buckling load, suggesting the 4800-element mesh is a reasonable compromise between speed and accuracy. The boundary conditions of the buckling simulation are schematically shown in the Figure 7. An 'Encastre' boundary condition is applied along the bottom edge, whilst for the top edge, only displacement in the $\mathrm{Y}$ direction is allowed and a load of $-1 \mathrm{~N}$ is applied on each element along the length of the top edge. Both out-of-plane displacement and rotation about the $X$ direction on the two side edges (indicated by thick black lines in Figure 7) are constrained. The buckling simulation uses the linear 'Perturbation - Buckle' method available in Abaqus ${ }^{\mathrm{TM}}$. The buckling load is calculated as the $1^{\text {st }}$ buckling mode eigenvalue, multiplied by the loads applied on the top edge [28].

For post-buckling analysis, the applied boundary conditions are the same as for the buckling 
analysis, but here the 'General - Riks' method [34, 35] is used instead. The nodal information of the buckled shape from the linear buckling simulation is imported into the 'Riks' postbuckling simulation as the imperfection of the geometry. Abaqus ${ }^{\mathrm{TM}}$ strength predictions are made using two different damage models already implemented in the software, namely the Hashin [36] and LaRC05 [37, 38] models.

Because the thickness (and therefore the areal density) of a steered fibre laminate is expected to increase after shearing, the mass of the resulting steered-fibre laminates will be slightly higher than the straight-fibre laminates and has to be modified in the simulations to provide an equal mass scenario for comparison purposes. To do this, a 'compensation factor', $C$, is introduced. This is equal to the ratio between the area of the initial sheet prior to shearing (see, for example, Figure $1 \mathrm{~A}$, the perimeter is highlighted by a thick blue line) and the final target steered fibre sheer, after shearing (see for example Figure $1 \mathrm{~B}, 300 \times 400 \mathrm{~mm}$ in this case, the perimeter is again highlighted by a thick blue line). These area values and the subsequent area ratio, $\mathrm{C}$, are automatically determined by the code. The thickness of straight-fibre laminates, $T_{s}$, is adjusted as follows

$$
\mathrm{T}_{\mathrm{s}}=\mathrm{T}_{0} \times \mathrm{N}_{\mathrm{p}} \times \mathrm{C}
$$

where $T_{0}$ is the thickness of the straight fibre plies, $N_{p}$ is number of plies and $C$ is the compensation factor. The bulk density of the material within the sheet is assumed to remain unaltered by the 2 -d steering process.

\section{Results and discussions}

Figure 8 shows fibre orientations of a steered pattern mapped into two distinct plies within the shell element's composite laminate section, created in Abaqus ${ }^{\mathrm{TM}}$. Figure 9 provides a summary of the buckling resistance of the carbon fibre laminates listed in Table 3 for the 
$300 \times 400 \mathrm{~mm}$ plates (Figure $7 \mathrm{a}$ ) by showing the normalised buckling loads against $\theta_{\max }$ (see Equation 6). The ideal equal-mass scenario, as described in Section 3.2, was used in the buckling investigation. The buckling load of the $\left[( \pm 45)_{4}\right]_{s}$ laminate is selected as the benchmark for the normalisation. Because the horizontal axis of the graph, $\theta_{\text {max }}$, applies only to those laminates containing steered-fibre plies, the load curves of all the straight-fibre laminates appear as a single point at 0 shear angle (unsheared plies). However, horizontal dashed straight lines extending from these points have been added to the graph simply to facilitate comparison with predictions for the VSPs. The relative improvements in the buckling load of layups containing steered-fibre plies initially increases with increasing maximum shear angle on the vertical edge of the horizontal generator path and then starts to drop after reaching a peak at a maximum shear angle of around $30^{\circ}$.

To facilitate discussion, the laminates can be classified into two categories: double-angle laminates containing only two sets of fibres and multi-angle laminates containing 4 sets of fibres. For double-angle laminates, when $\theta_{\max } \approx 30^{\circ}$ the steered fibre laminate $\left[( \pm \mathrm{SFP})_{4}\right]_{s}$ (brown line) shows an improved buckling load, about $\sim 5 \%$ higher than the $\left[( \pm 45)_{4}\right]_{s}$ straightfibre laminate (light orange line), though it offers very little improvement compared with the $\left[(90 / 0)_{4}\right]_{s}$ laminate (light grey line). The buckling loads of all the multi-angle laminates are improved compared to the benchmark $\left[( \pm 45)_{4}\right]_{s}$ laminate, presumably because the fibres strengthen the whole structure in multiple directions. As expected, the layup sequence is important to buckling resistance, e.g. the $\left[( \pm 45)_{2} /(90 / 0)_{2}\right]_{s}$ (light blue line) produces the best buckling-resistance of all the investigated straight-fibre laminates, significantly better than the $\left[(90 / 0)_{2} /( \pm 45)_{2}\right]_{s}$ layup (dark orange line) which is approximately $10 \%$ lower. Apparently, placing the $( \pm 45)$ plies at the outer surface of the $\left[( \pm 45)_{2} /(90 / 0)_{2}\right]_{s}$ laminate provides improved resistance to the torsional deformations associated with buckling of the panel [8]. 
The $\left[( \pm 45)_{2} /( \pm 30) /( \pm 45) /( \pm 15)\right]_{s}$ laminate (dark grey line), was previously reported to offer the optimum buckling resistance in $[5,7,9]$, though here is found to rank second amongst the purely straight-fibre laminates considered in this investigation, i.e. behind the quasi-isotropic $\left[( \pm 45)_{2} /(90 / 0)_{2}\right]_{s}$ laminate.

The most significant results are found when the steered-fibre plies are combined with straight-fibre plies to create hybrid steered/straight fibre laminates. The hybrid laminate $\left(\left[( \pm \mathrm{SFP})_{2} /(90 / 0)_{2}\right] \mathrm{s}\right)$ (red line) offers an improvement of $5.4 \%$ in the buckling load, compared with the best conventional straight fibre laminate, i.e. $\left[( \pm 45)_{2} /(90 / 0)_{2}\right]_{s}$ (blue line), and by $9.3 \%$ compared to the 'optimum' straight-fibre laminate proposed in $[5,7,9]$ i.e. the $\left[( \pm 45)_{2} /( \pm 30) /( \pm 45) /( \pm 15)\right]_{s}$ laminate (dark grey line). To provide context, using the previous investigation results summarised in Table 1, it is worth noting that the buckling load of the VSP proposed in [9] was found to be approximately $10 \%$ higher than that of the $\left[( \pm 45)_{2} /( \pm 30) /( \pm 45) /( \pm 15)\right]_{s}$ straight fibre laminate, and so this result compares very closely to the $9.3 \%$ improvement by the $\left(\left[( \pm \mathrm{SFP})_{2} /(90 / 0)_{2}\right] \mathrm{s}\right)$ (red line) laminate generated in this study.

Considering panels containing a central hole (see Table 1 and Table 4), the improvement in buckling load of the steered/straight fibre hybrid laminates becomes even more significant; $7.4 \%$ and $14.0 \%$ higher compared to the $\left[( \pm 45)_{2} /(90 / 0)_{2}\right]_{s}$ and $\left[( \pm 45)_{2} /( \pm 30) /( \pm 45) /( \pm 15)\right]_{s}$ laminates respectively. The effect of the central hole is to decrease the buckling resistance of all the panels, as indicated in Table 4. However, fibre steering is found to reduce the relative magnitude of this negative effect. The presence of the steered fibre plies in the laminate reduces the drop in performance to about $5 \%$, less than half the drop of about $11 \%$ experienced by the straight-fibre laminates containing a central hole.

According to these results, the optimal steered pattern produced by 2 -d pin-jointed net 
forming kinematics is that with $\theta_{\max } \approx 30^{\circ}$. Hence, the steered/straight fibre hybrid laminate, $\left[( \pm S F P)_{2} /(90 / 0)_{2}\right]_{s}$, was selected for the Stage 2 investigation, i.e. post-buckling performance, and was compared with the second best laminate analysed in this investigation; the quasi-isotropic straight-fibre laminate $\left[( \pm 45)_{2} /(90 / 0)_{2}\right]_{s}$. The layup sequence of half of the symmetric laminate $\left[( \pm \mathrm{SFP})_{2} /(90 / 0)_{2}\right]_{\mathrm{s}}$ is schematically shown in Figure 10 . Note that, because the maximum shear angle, $\theta_{\max } \approx 30^{\circ}$ as shown in Figure 6 , the orientation of the fibres is $\approx 45^{\circ}$ at the centre of steered pattern and gradually reaches $\approx 60^{\circ}$ at the vertical edge along the horizontal centreline. Therefore, as an addition to the Stage 2 investigation, an extra straight-fibre laminate, namely $\left[( \pm 60)_{2} /(90 / 0)_{2}\right]_{s}$, is also included in the comparison, in order to further examine the effect of fibre steering. Both carbon and glass fibres are considered and use the properties listed in Table 2. Post-buckling properties were examined by employing boundary conditions, as discussed in Section 3.

Table 5 summarises the loads at the $1^{\text {st }}$ buckling mode and also at the failure predicted by both the Hashin and LaRCO5 damage models, for the straight fibre laminates and the hybrid steered/straight fibre laminate (for both carbon and glass). Figure 11 demonstrates the typical geometries for the $1^{\text {st }}$ and $2^{\text {nd }}$ buckling modes of the hybrid steered/straight carbon fibre laminate predicted by post-buckling simulations. Corresponding force versus displacement predictions are shown in Figure 12 . The change in gradient and the corresponding transition from linear to non-linear force versus displacement curves indicate the onset of the $1^{\text {st }}$ and $2^{\text {nd }}$ buckling modes. The failure load is determined by the point that the damage factors of the Hashin and LaRC05 damage models rise above 1.

From Table 5, it can be seen that the hybrid steered/straight fibre laminate has a better buckling and failure load, compared to the straight-fibre laminates. For the carbon fibre laminates, the load at the onset of the $1^{\text {st }}$ buckling mode of the hybrid laminates is improved 
by $7.4 \%$, compared to the QI straight fibre laminate. Predictions of both the Hashin and LaRC05 damage models reflect similar levels of improvement for the failure load of $4.8 \%$ and $4.4 \%$ respectively. The difference in the predicted failure loads from these two damage models can perhaps be ascribed to the fact that the Hashin model omits the effect of in-plane shear on fibre failure and also neglects the increased shear stress caused by transverse compression [39]. It is also worth noting that the hybrid laminates have slightly higher buckling loads than the straight-fibre laminate, $\left[( \pm 60)_{2} /(90 / 0)_{2}\right]_{s}$, and also an improvement of about $10 \%$ for the failure load. This comparison is of particular interest because the optimal VSP analysed in this investigation also has fibre orientations are $\pm 60^{\circ}$ near the edge of the panel. This improvement emphasizes the positive effects of a curvilinear fibre path, particularly in terms of strength, compared to that obtained when using conventional straight-fibre laminates.

Figure 13 indicates the damage initiation locations within the $\left[( \pm \mathrm{SFP})_{2} /(90 / 0)_{2}\right]_{s}$ hybrid laminate. The failure occurs initially from the outer layers (+SFP), while the inner (90) and (0) plies are unaffected. Post buckling, out-of-plane deformation of the panel means that the outer plies suffer more stress and strain due to torsion and bending [7]. Figure 14 shows the distribution of the stress (S22) along the compressive loading direction on the outer $(+45)$ ply in the $\left[( \pm 45)_{2} /(90 / 0)_{2}\right]_{S}$ laminate and the outer (+SFP) ply in the $\left[( \pm S F P)_{2} /(90 / 0)_{2}\right]_{s}$ laminate, at their buckling loads. It can be seen that the continuously changing fibre orientations in the (+SFP) ply lead to a more uniform stress distributions and lower stress levels, compared to the straight-fibre $(+45)$ ply in the quasi-isotropic laminates. Furthermore, the steered fibre path redistributes loads from the highly loaded central region to the edges, which are stiffer both due to the boundary conditions (no out-of-plane displacement on the vertical edges) and the fibre orientations. Hence, the hybrid laminates $\left(\left[( \pm \mathrm{SFP})_{2} /(90 / 0)_{2}\right]_{s}\right)$ achieve improved 
buckling and failure loads. Similar effects were reported in previous studies [7, 9].

According to the simulation results produced using the properties for glass-epoxy laminates in Table 5, the steered/straight hybrid laminates achieves similar improvement in buckling load at $5.7 \%$, compared to the carbon-epoxy laminates. On the other hand, the increase in failure strength produced by the steered laminates becomes more significant when moving from carbon to glass composites; about a $5 \%$ increase for carbon-epoxy compared to $10 \%$ increase for glass-epoxy. 


\section{Conclusions}

The design tool, SteerFab, has been used to demonstrate the numerical design and analysis of steered-fibre laminate panels. Predictions from the first stage screening showed the $\left[( \pm \mathrm{SFP})_{2} /(90 / 0)_{2}\right]_{s}$ layup demonstrated significant improvements in buckling load. For a panel with a hole at the centre, the steered-fibre plies reduce the negative effect of the cut out and lead to further relative improvements in the buckling load of VSP's in comparison with equivalent straight-fibre laminates containing a central hole. More specifically, compared to conventional quasi-isotropic laminates $\left[( \pm 45)_{2} /(90 / 0)_{2}\right]_{\mathrm{S}}$ containing a hole, or the 'optimum' layup suggested in $[7,9]$ i.e. $\left(\left[( \pm 45)_{2} /( \pm 30) /( \pm 45) /( \pm 15)\right]_{s}\right)$ containing a hole, the buckling load of the steered hybrid laminate is improved by $7.4 \%$ and $14.0 \%$ respectively, at the equal-mass scenario. Post-buckling simulations revealed that the steered carbon-fibre hybrid laminates improve failure load by about 5\%, compared to conventional Ql layup. Furthermore, in comparison with the carbon composites, the glass composites show less improvement ( $6 \%)$ in buckling response and more significant improvement ( 10\%) in damage response. These numerical results provide guidelines by which to examine these ideas in practice via experimental investigation. The manufacture and testing of actual fabric steered-hybrid laminates will be the subject of a subsequent investigation.

\section{Acknowledgements}

Funding (EP/P021573/1) for the project '2-D Forming of Low Cost Steered Fibre Laminates' from the Engineering and Physical Sciences Research Council is gratefully acknowledged. 
(A)

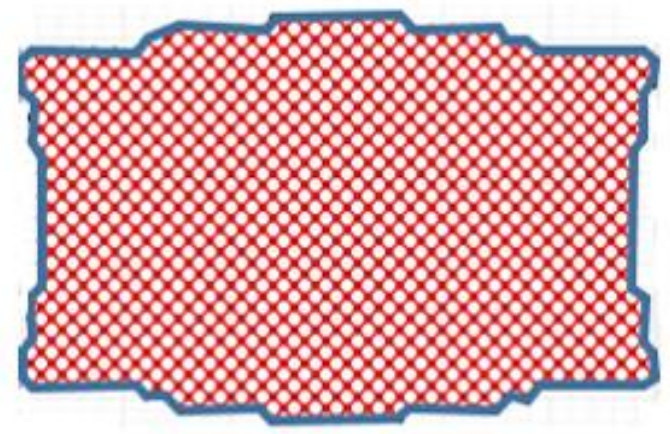

(C)

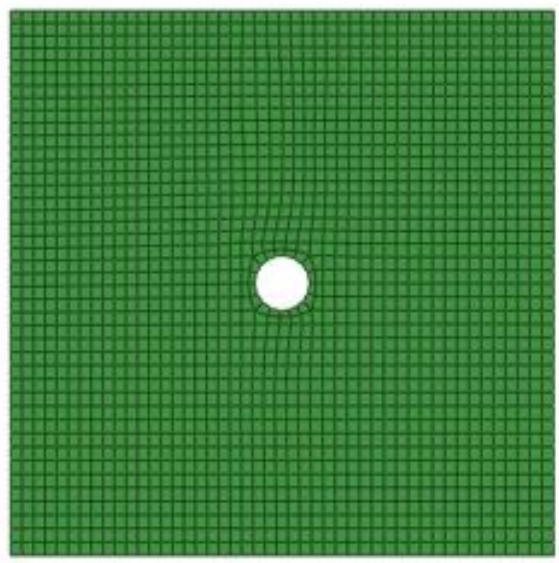

(E)

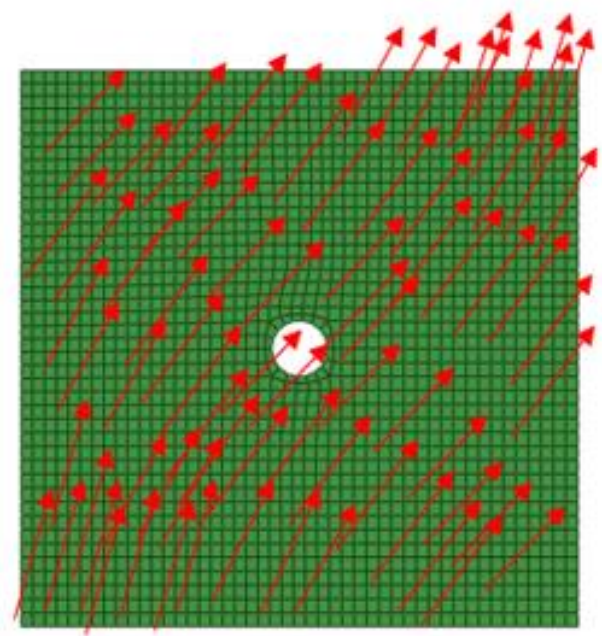

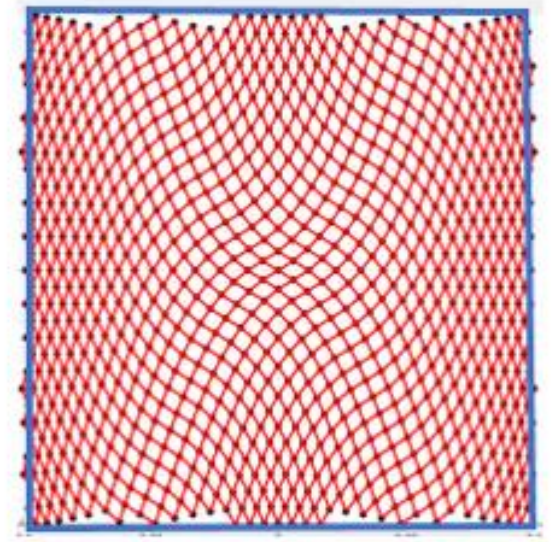

(B)

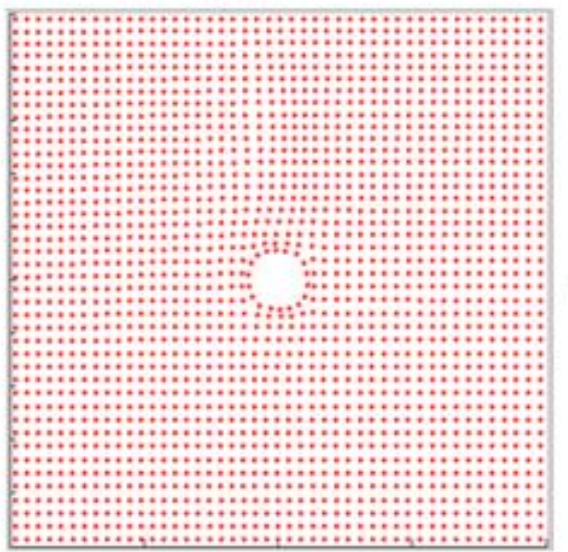

(D)

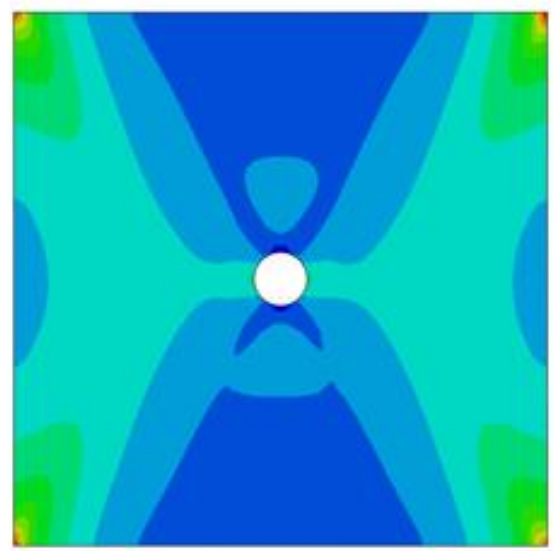

(F)

Figure 1: (A) mesh of initial unsteered sheet showing original perimeter shape prior to 2-d forming, (B) steered-fibre pattern after 2-d forming within the target perimeter shape, (C) finite element mesh of same perimeter size and shape as the target perimeter shape, (D) coordinates of the centroid of each finite element are calculated for use by the mapping algorithm, (E) fibre angle and sheet thickness of the fibre directions are mapped at the position of each element centroid from the steered fibre pattern to the finite element mesh (the fibre directions of those fibres running from lower left to upper right in the steered pattern are shown here), (F) numerical simulation in Abaqus ${ }^{\mathrm{TM}}$, here the colour map represents a typical stress distribution resulting from a steered fibre laminate. 


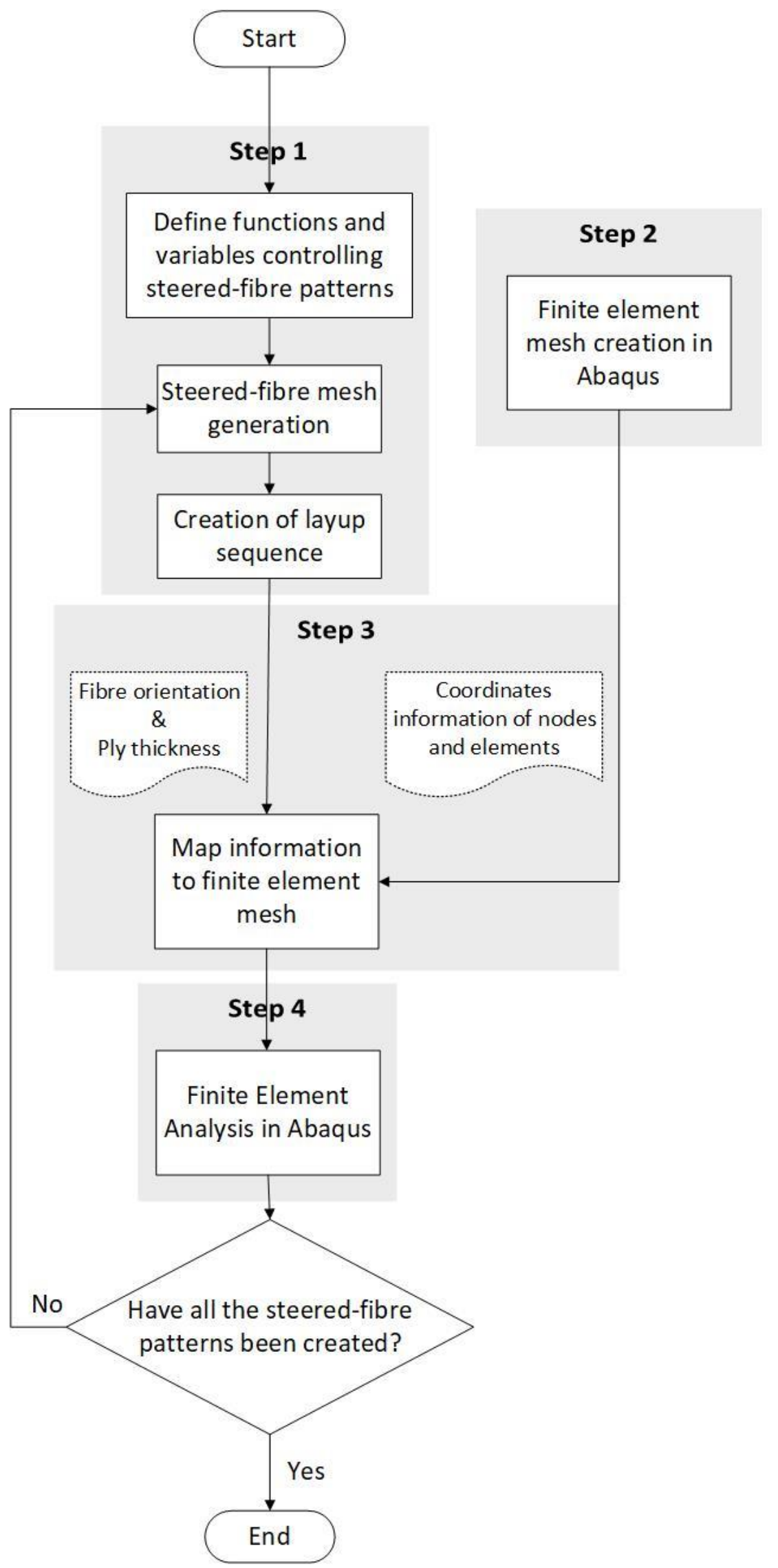

Figure 2 The flow chart of the SteerFab code in this design study 
(A)

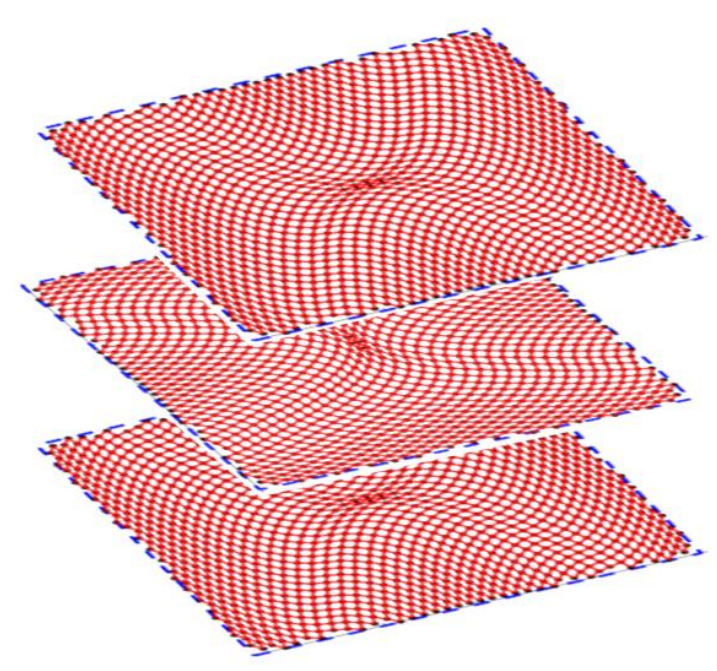

(B)

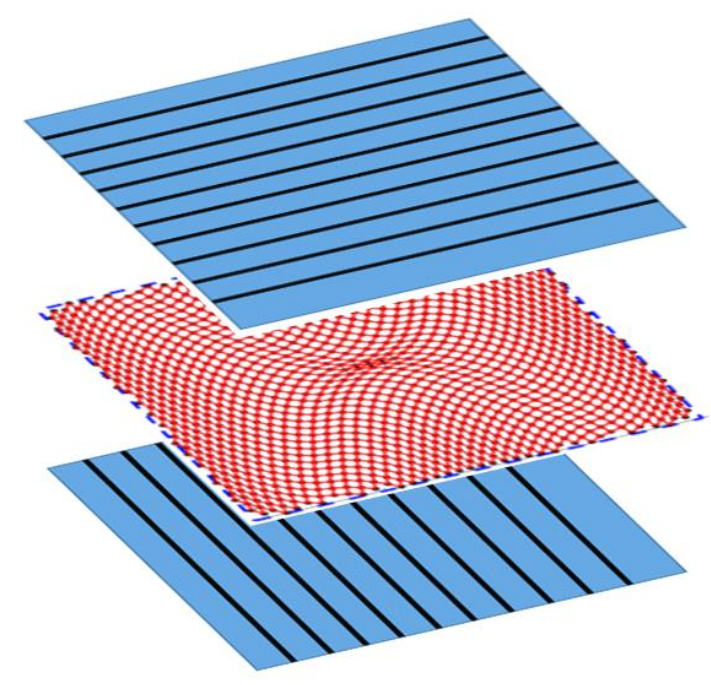

Figure 3 Schematics of laminates consisting of: $(A)$ multiple-steered fibre sheets and $(B)$ both steered and straight fibre sheets

(A)

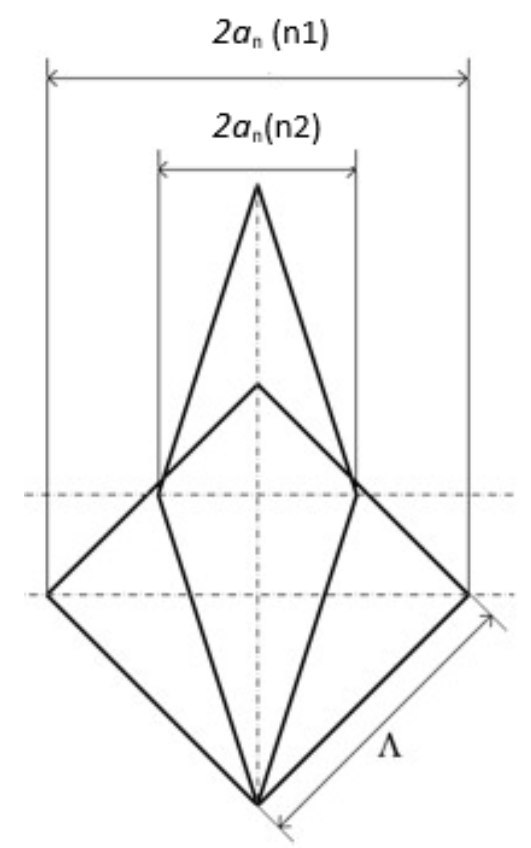

(B)

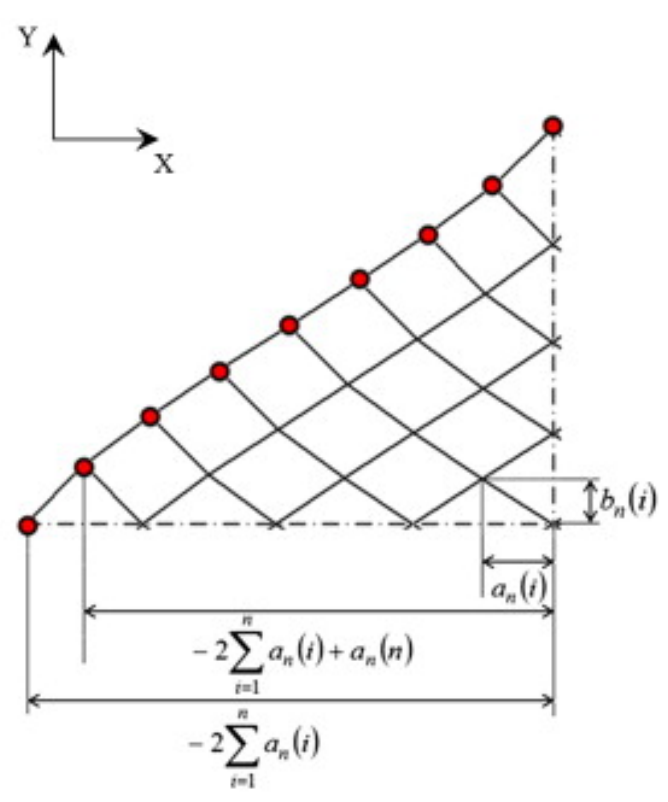

Figure 4. Schematic showing: (A) the different diagonal lengths of the undeformed and sheared elements, (B) elements and nodal coordinates generated by SteerFab (reproduced from [1]) 
(A)

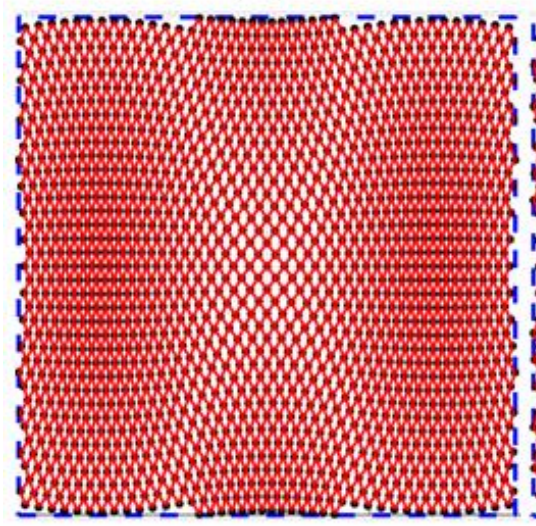

(B)

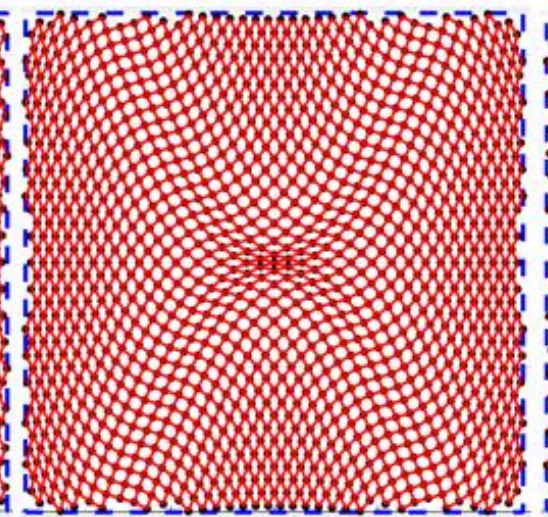

(C)

Figure 5 Different steered patterns generated in SteerFab by various forms of control functions, $\chi$, including: (A) a parabolic function, (B) a high-order polynomial function and (C) a trigonometric function

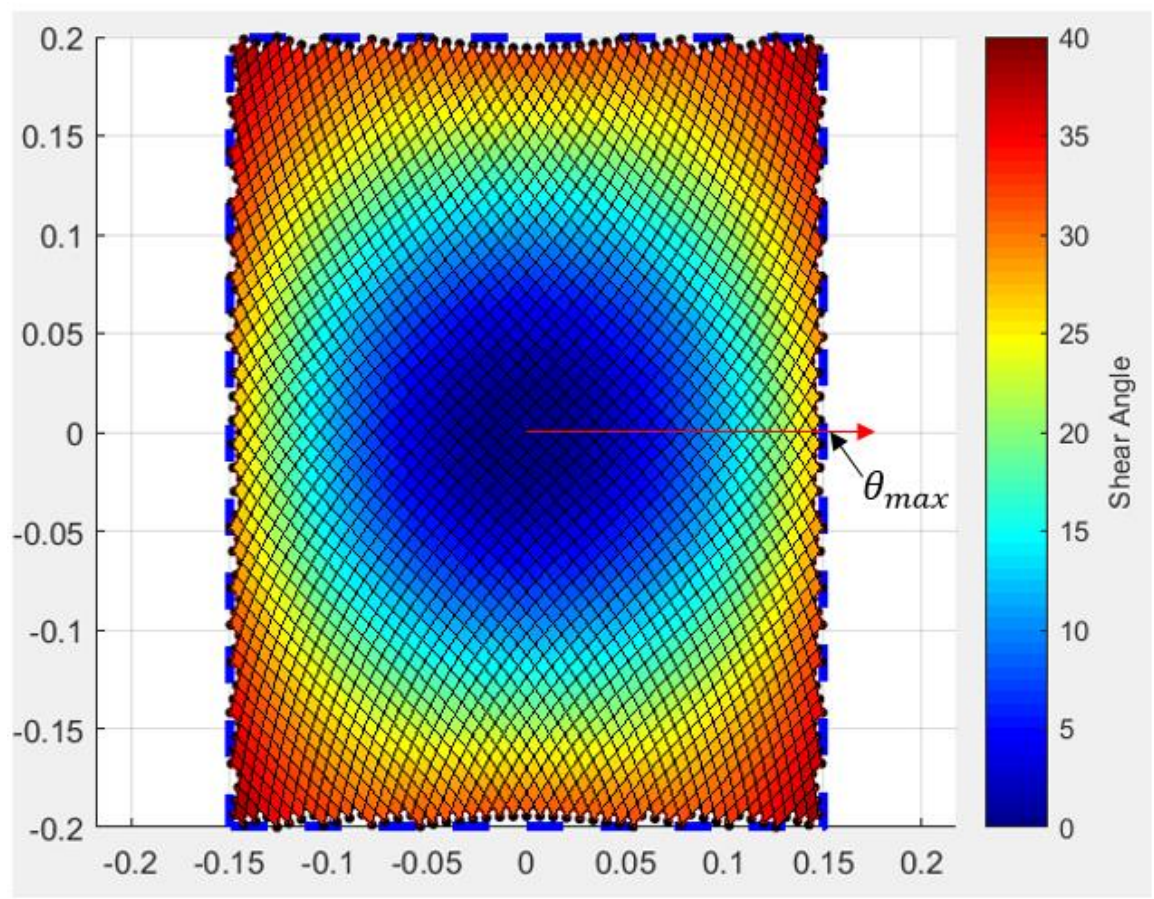

Figure 6. A steered pattern with the indication of max shear angle on the vertical edge of the horizontal generator path $\left(\theta_{\max } \approx 30^{\circ}\right)$. Note that $\theta_{\max }$ is not necessarily the highest shear angle generated across the entire sheet, as can be seen in this colour map of the shear angle. 
(A)

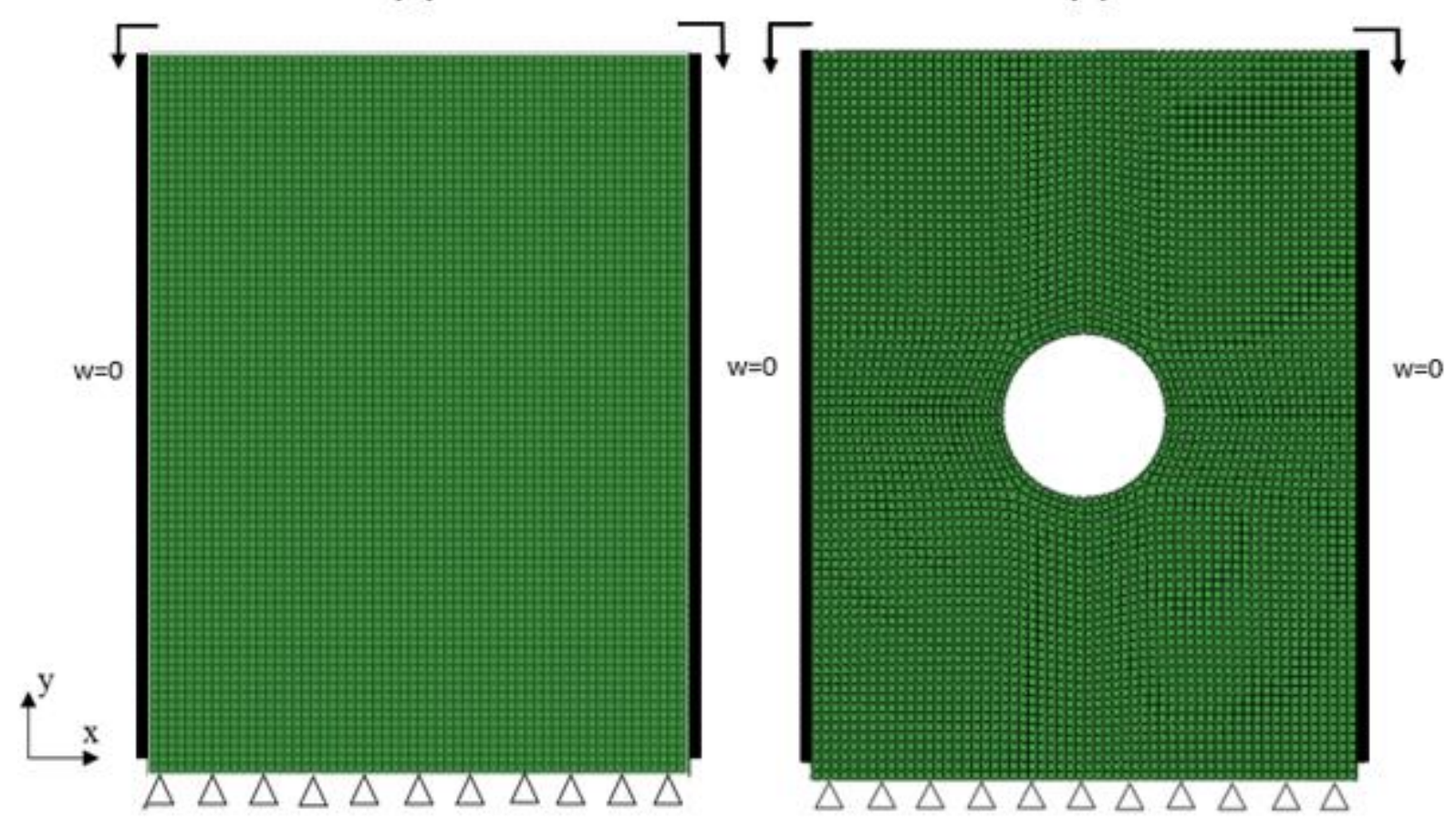

Figure 7. Meshes of the FE models and schematics of the applied boundary conditions for the $300 \mathrm{~mm} \times 400 \mathrm{~mm}$ plates, (A) without a central hole and (B) with a central hole (diameter $90 \mathrm{~mm}$ )

(A)

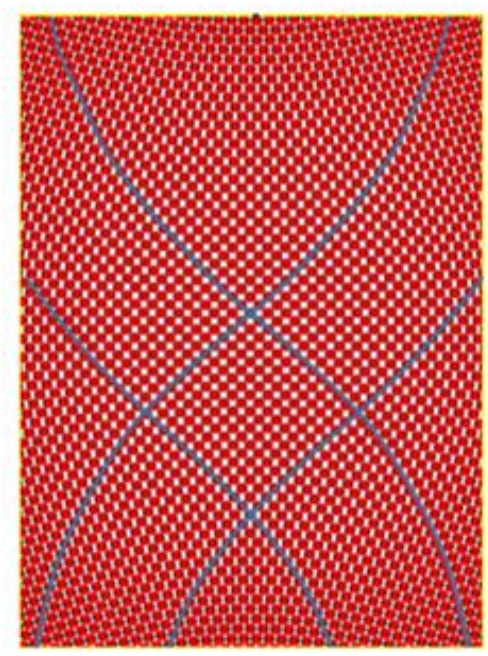

(B)

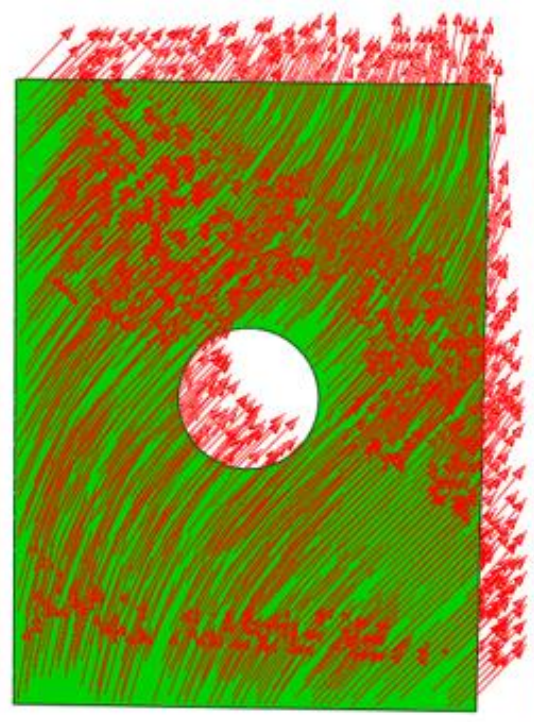

(C)

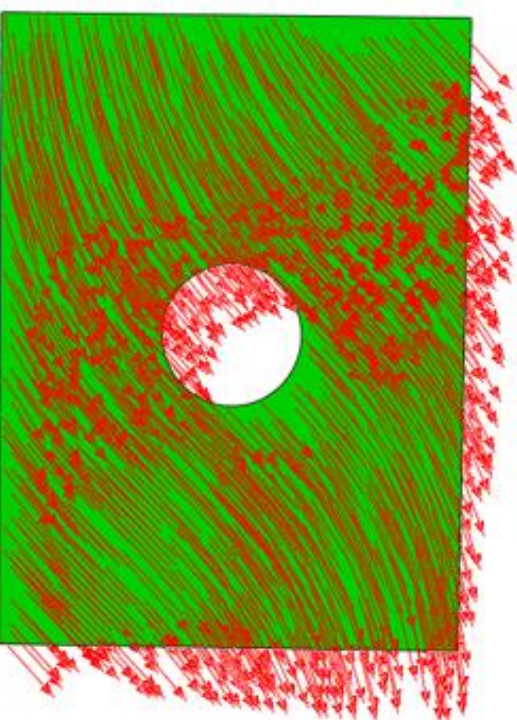

Figure 8 Comparison between $(A)$ a $(300 \mathrm{~mm} \times 400 \mathrm{~mm})$ steered fibre pattern generated by SteerFab and $(B)$ orientations of fibres running from lower left to upper right mapped to one ply within element section and $(C)$ orientations of fibres running from upper left to lower right mapped to another ply within element section 


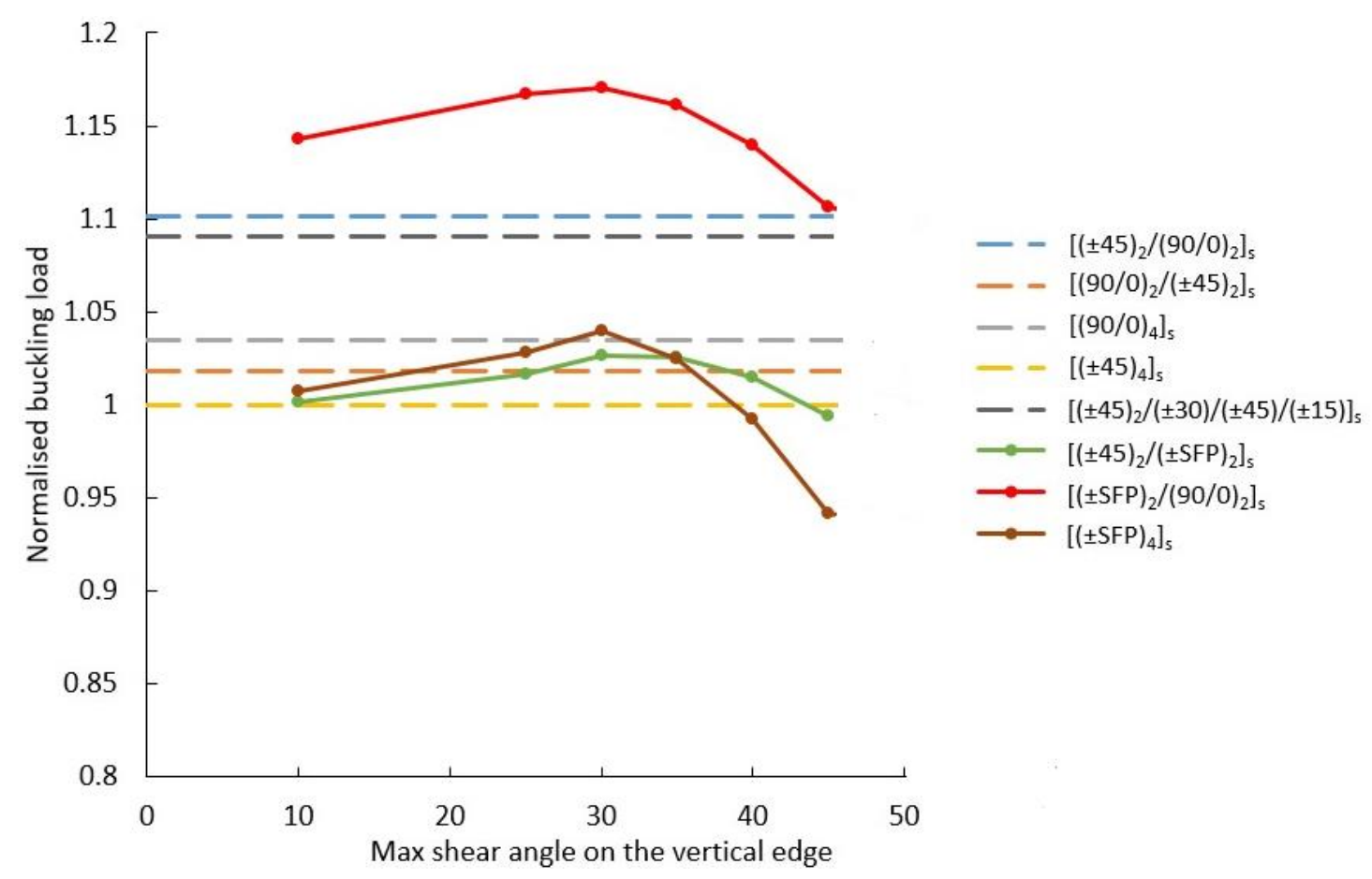

Figure 9. Normalised buckling load versus $\theta_{\max }$, the 'maximum shear angle at the end of the horizontal generator path', for all the investigated laminates (a $300 \mathrm{~mm} \times 400 \mathrm{~mm}$ plate). Each data point was normalised by the buckling load of the $\left[( \pm 45)_{4}\right] \mathrm{s}$ laminate. Straight fibre layups are indicated by the dashed lines.

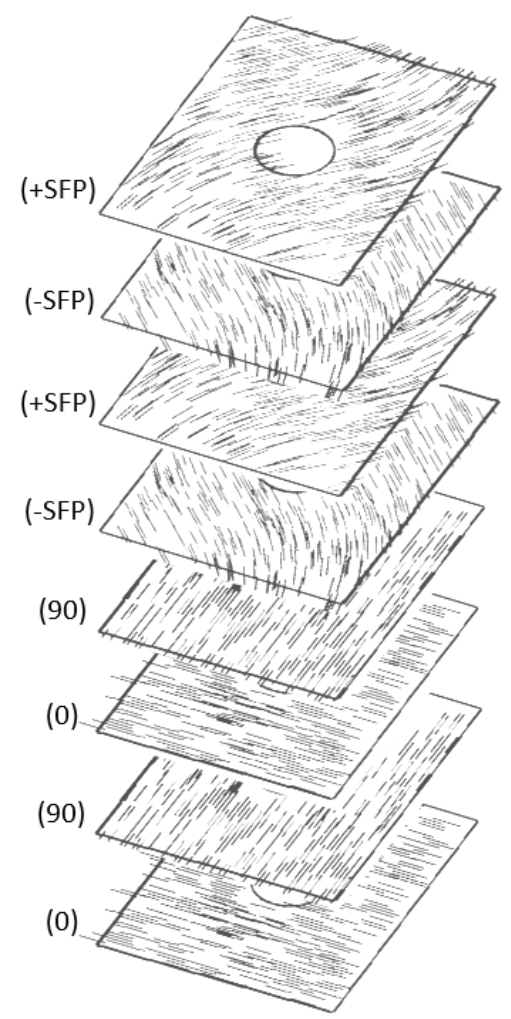

Figure 10. The layup sequence of the half of the symmetric $\left[( \pm \mathrm{SFP})_{2} /(90 / 0)_{2}\right]_{s}$ laminate. Black lines indicate the fibre orientation of each ply. This orientation information is directly output from the material orientations of elements in the finite element model. 
(A)

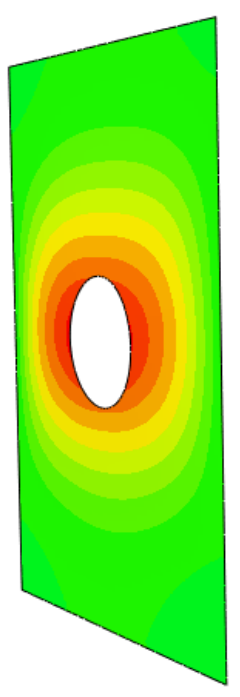

(B)

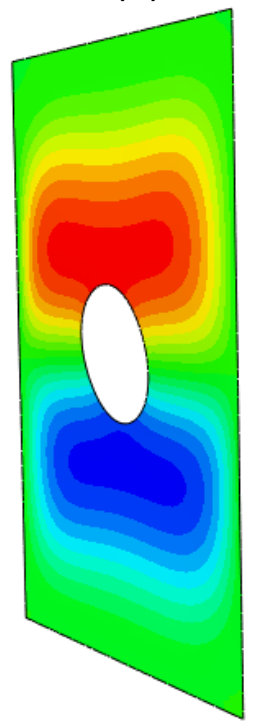

$\mathrm{U}, \mathrm{U} 3 \quad(\mathrm{~m})$

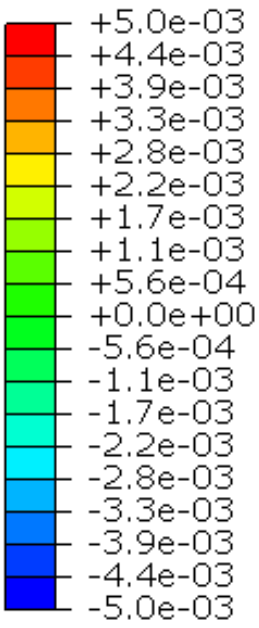

Figure 11. (A) $1^{\text {st }}$ and (B) $2^{\text {nd }}$ mode buckled geometries of the hybrid steered/straight fibre laminate $\left(\left[( \pm \mathrm{SFP})_{2} /(90 / 0)_{2}\right]_{s}\right)$ specimens from post-buckling simulations in Abaqus ${ }^{\mathrm{TM}}$.

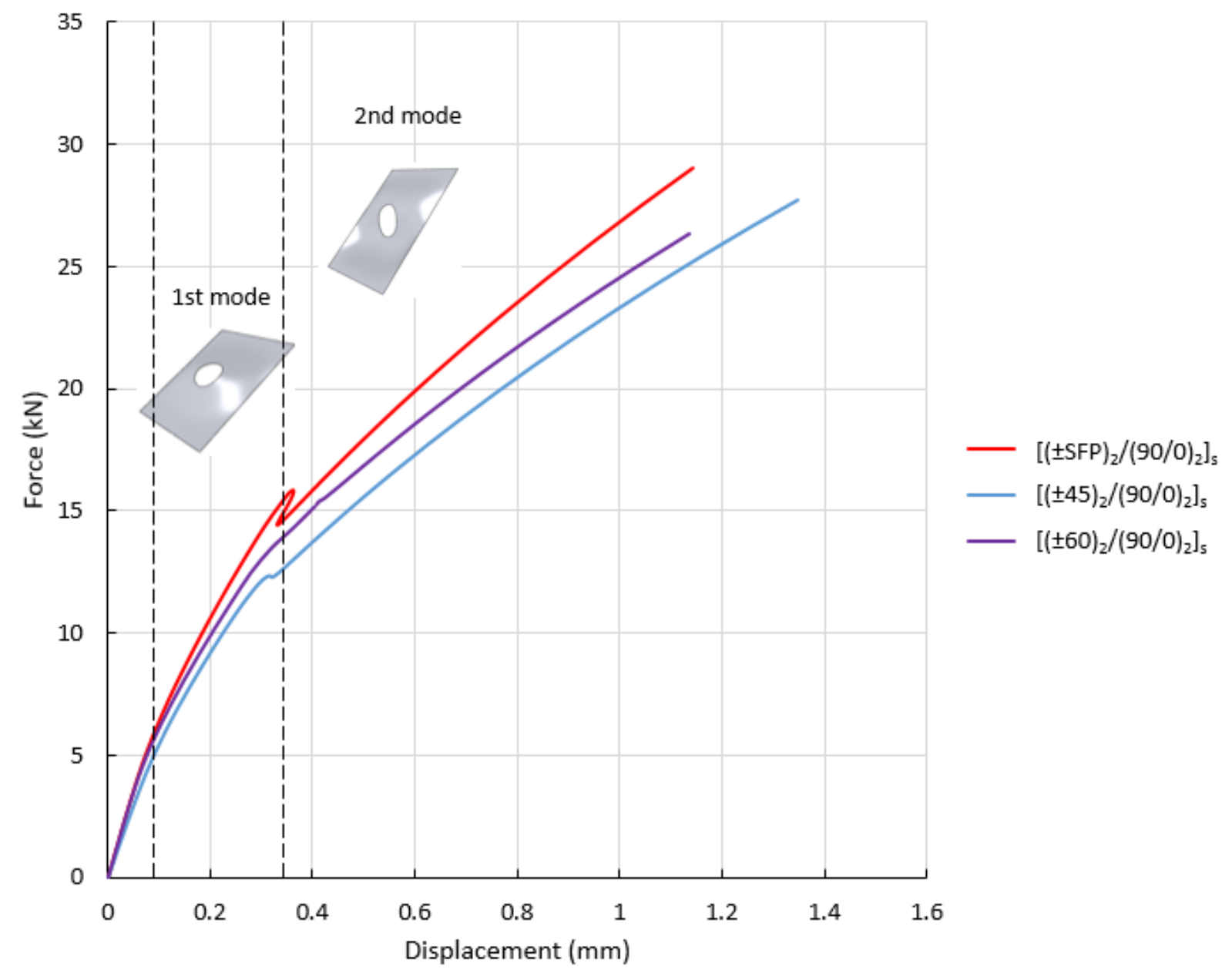

Figure 12 Typical Force-Displacement curves from post-buckling simulations (LaRC05 damage model) of the carbon fibre $\left[( \pm 45)_{2} /(90 / 0)_{2}\right]_{s},\left[( \pm 60)_{2} /(90 / 0)_{2}\right]_{s}$, and $\left[( \pm S F P)_{2} /(90 / 0)_{2}\right]_{s}$ laminates 
(A) +SFP ply
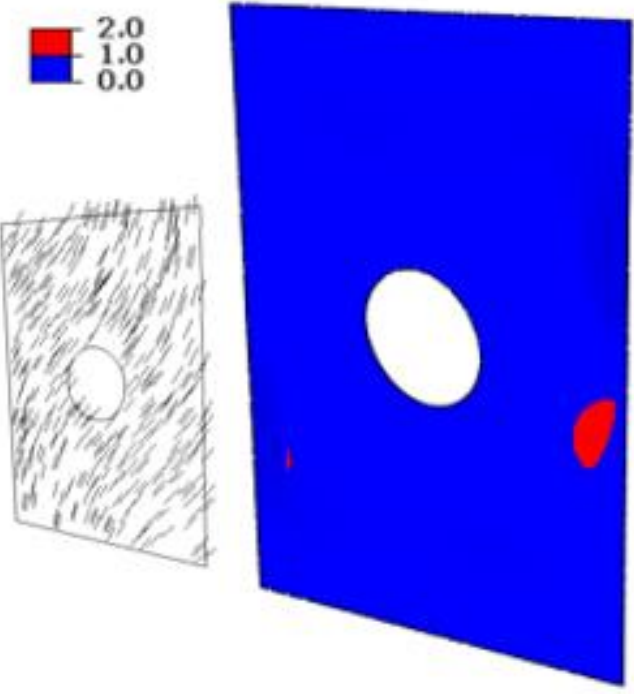

(C) 90 ply

UVARM1

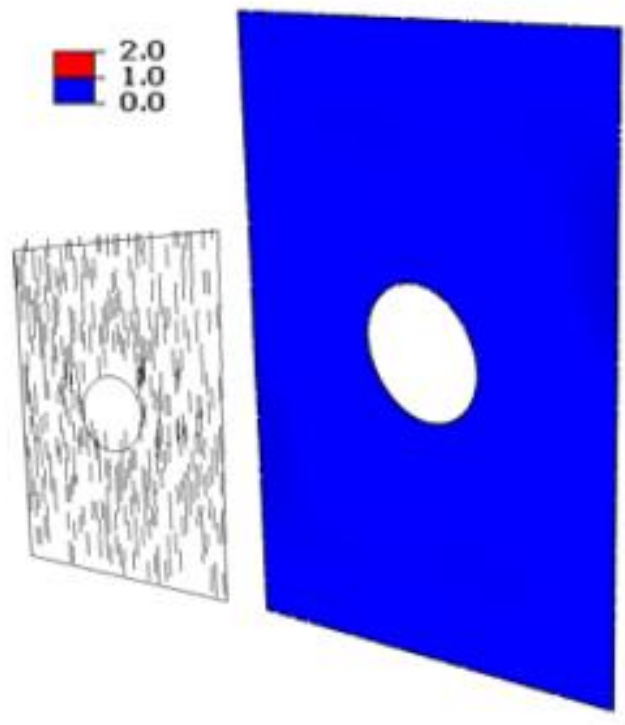

UVARM1

(B) -SFP ply

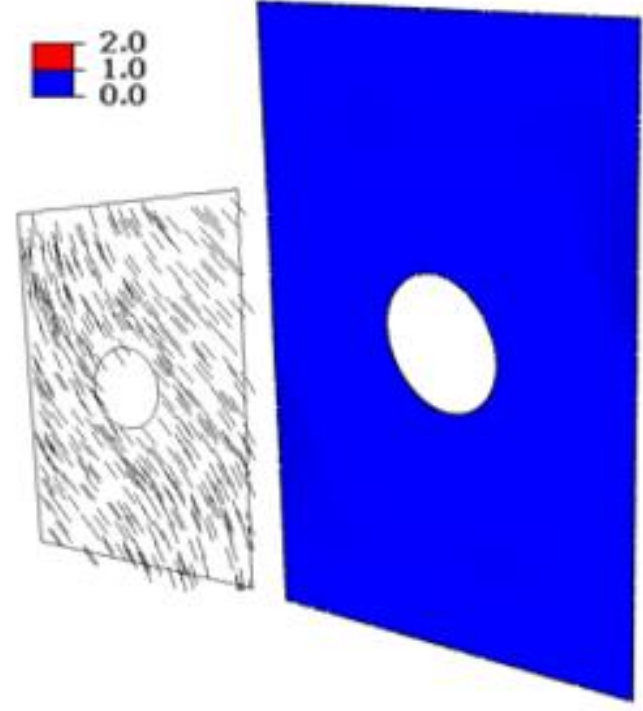

(D) 0 ply

UVARM1

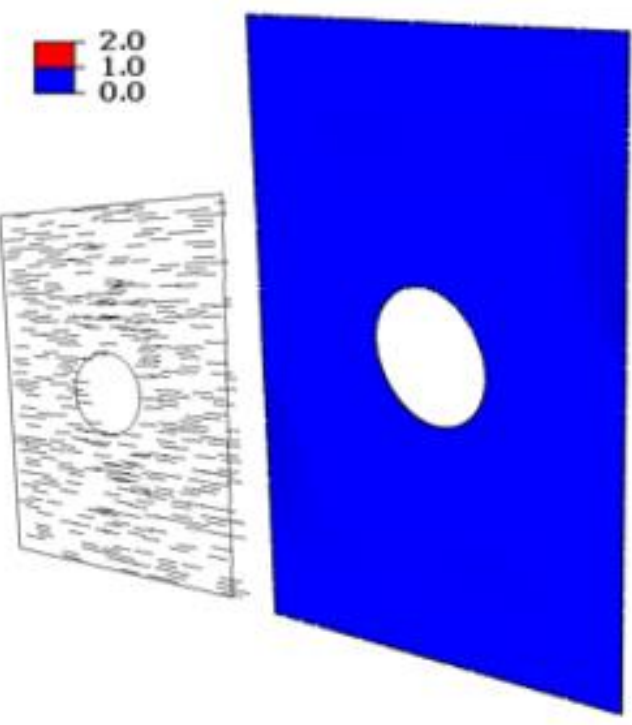

Figure 13. The coloured images show the damage factor distribution in each ply of the hybrid laminate $\left[( \pm \mathrm{SFP})_{2} /(90 / 0)_{2}\right]_{s}$ (for just one side of the laminate). The damage initiation locations predicted by the LaRC05 model within each ply are shown in red at the failure load of $29.30 \mathrm{kN}$. The distribution of fibre orientations in each ply is also shown, represented by black lines in the adjacent images. 
(A)

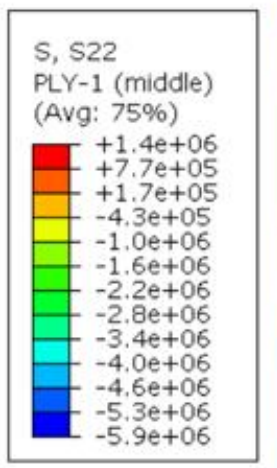

$(+45)$

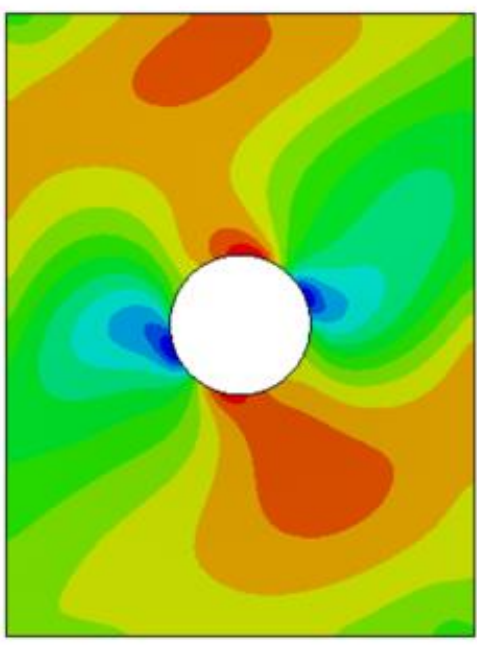

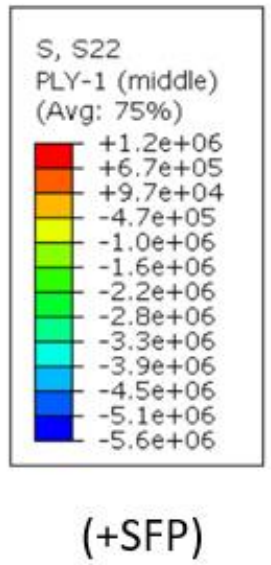

$(+\mathrm{SFP})$
(B)

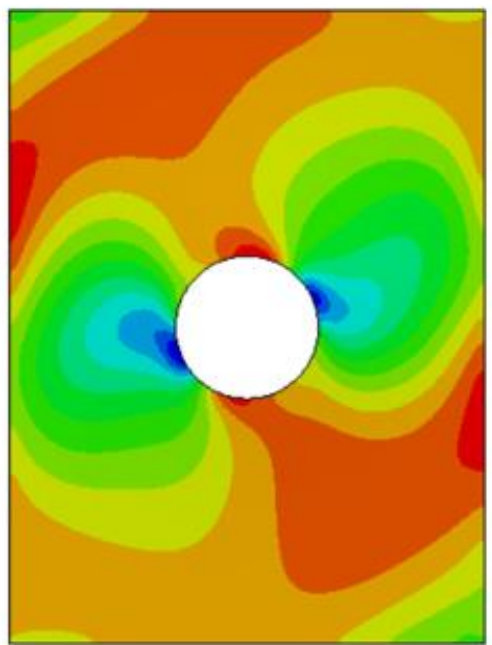

Figure 14 The stress (S22) distributions at compressive loading direction on: $(A)$ the outer $(+45)$ ply in the $\left[( \pm 45)_{2} /(90 / 0)_{2}\right]_{s}$ laminate at its buckling load of $5.7 \mathrm{kN}$ and $(\mathrm{B})$ the outer (+SFP) ply in the $\left[( \pm \mathrm{SFP})_{2} /(90 / 0)_{2}\right]_{\mathrm{s}}$ laminate at its buckling load of $6.1 \mathrm{kN}$. 
Tables

Table 1. Improvement ratio of buckling load for rectangular VSPs from previous studies and the present paper

\begin{tabular}{|c|c|c|c|c|c|}
\hline $\begin{array}{l}\text { Data } \\
\text { source }\end{array}$ & VSP & $\begin{array}{l}\text { Benchmark straight- } \\
\text { fibre laminates } \\
\text { (buckling load) }\end{array}$ & Boundary conditions & $\begin{array}{l}\text { Aspect ratio } \\
\text { (Length/Width) }\end{array}$ & $\begin{array}{l}\text { Improvement } \\
\text { ratio }\end{array}$ \\
\hline$[10]$ & $\operatorname{VS}(x, y)$ & $\begin{array}{c}{[ \pm 45 / 0 / 90]_{s}} \\
(\mathrm{n} / \mathrm{a})^{\Delta} \\
\end{array}$ & Four edges are simply supported. & $\begin{array}{c}1: 1 \\
(\mathrm{n} / \mathrm{a})^{\Delta}\end{array}$ & $189 \%$ \\
\hline \multirow{2}{*}{ [6] } & \multirow{2}{*}[90\pm<0|75>]{$_{3 \mathrm{~s}}$} & \multirow{2}{*}{$\begin{array}{l}{[ \pm 45]_{3 \mathrm{~s}}} \\
(\mathrm{n} / \mathrm{a})^{\Delta}\end{array}$} & \multirow{2}{*}{ Four edges are simply supported. } & $\begin{array}{c}1: 1 \\
(\mathrm{n} / \mathrm{a})^{\Delta}\end{array}$ & $80 \%$ \\
\hline & & & & $\begin{array}{c}2: 1 \\
(\mathrm{n} / \mathrm{a})^{\Delta}\end{array}$ & $66 \%$ \\
\hline [8] & $\begin{array}{c}\mathrm{L}:(0 \pm<45|0|(\mathrm{a} / 2)>) \\
\mathrm{T}:(90 \pm<45|0|(\mathrm{b} / 2)>) \\
{\left[\mathrm{L} / \mathrm{L}_{\text {mirror }} / \mathrm{T} / \mathrm{T}_{\text {mirror }}\right]_{\mathrm{s}}}\end{array}$ & $\begin{array}{c}{[ \pm 45 / 0 / 90]_{s}} \\
(15.58 \mathrm{kN})\end{array}$ & $\begin{array}{l}\text { Lower edge is in 'Encastre' condition; Upper edge can } \\
\text { only have movements at loading direction; Two side } \\
\text { edges are constrained for out-of-plane displacement } \\
\text { and for rotation about transverse directions. }\end{array}$ & $\begin{array}{c}2: 1 \\
(400 \mathrm{~mm} / 200 \mathrm{~mm})\end{array}$ & $18 \%$ \\
\hline [11] & {$[ \pm<45 \mid 26>]_{45}$} & $\begin{array}{c}{[+45 / 0 /-45 / 90]_{2 s}} \\
(n / a)^{\Delta}\end{array}$ & Four edges are simply supported. & $\begin{array}{c}8: 5 \\
(406 \mathrm{~mm} / 254 \mathrm{~mm})\end{array}$ & $56 \%$ \\
\hline$[12]$ & $\begin{array}{l}{[ \pm<49|41>/ \pm<48| 61>/} \\
\pm<57|73>/ \pm<72| 77>] \mathrm{s}\end{array}$ & $\begin{array}{c}{[+45 / 0 /-45 / 90]_{2 S}} \\
(11.52 \mathrm{kN})\end{array}$ & Four edges are simply supported. & $\begin{array}{c}8: 5 \\
(406 \mathrm{~mm} / 254 \mathrm{~mm})\end{array}$ & $45 \%$ \\
\hline [9] & $\begin{array}{c}{\left[ \pm 45 / 0 \pm<45 \mid 60>_{2} /\right.} \\
0 \pm<30|15>/ 0 \pm<45| 60>]_{s}\end{array}$ & $\begin{array}{c}{\left[ \pm 45_{2} / \pm 30 / \pm 45 / \pm 15\right]_{\mathrm{s}}} \\
(14.80 \mathrm{kN})\end{array}$ & $\begin{array}{l}\text { Lower edge is in 'Encastre' condition; Upper edge can } \\
\text { only have movements at loading direction; Two side } \\
\text { edges are constrained for out-of-plane displacement } \\
\text { and for rotation about transverse directions. }\end{array}$ & $\begin{array}{c}4: 3 \\
(508 \mathrm{~mm} / 381 \mathrm{~mm})\end{array}$ & $10 \%$ \\
\hline \multirow{2}{*}{$\begin{array}{l}\text { Present } \\
\text { paper }\end{array}$} & \multirow{2}{*}[(\pm\mathrm{SFP})_{2}/(90/0)_{2}]{$_{\mathrm{s}}$} & $\begin{array}{c}{\left[ \pm 45_{2} / \pm 30 / \pm 45 / \pm 15\right]_{s}} \\
(5.96 \mathrm{kN})\end{array}$ & \multirow{2}{*}{$\begin{array}{l}\text { Lower edge is in 'Encastre' condition; Upper edge can } \\
\text { only have movements at loading direction; Two side } \\
\text { edges are constrained for out-of-plane displacement } \\
\text { and for rotation about transverse directions. }\end{array}$} & \multirow{2}{*}{$\begin{array}{c}4: 3 \\
(400 \mathrm{~mm} / 300 \mathrm{~mm})\end{array}$} & $9 \%(14 \% *)$ \\
\hline & & $\begin{array}{c}{\left[( \pm 45)_{2} /(90 / 0)_{2}\right]_{s}} \\
(6.17 \mathrm{kN})\end{array}$ & & & $5 \%(7 \% *)$ \\
\hline
\end{tabular}

*The values in the brackets are from a same-size panel with a centre hole.

${ }^{\Delta}$ There are no detailed values reported in the corresponding literature. 
Table 2 Mechanical properties of the carbon and glass composites

\begin{tabular}{|c|c|c|}
\hline Materials & AS4/9773 carbon fibre-epoxy system & E glass fibre-epoxy system \\
\hline Data source & {$[9]$} & {$[33]$} \\
\hline $\begin{array}{c}\text { Material } \\
\text { properties* }\end{array}$ & $\begin{array}{c}\mathrm{E}_{11}: 129.8 \mathrm{GPa}_{22}: 9.2 \mathrm{GPa}_{12}: 0.36 \mathrm{G}_{12}: 5.1 \mathrm{GPa} \\
\mathrm{X}_{\mathrm{t}}: 2070 \mathrm{MPa} \mathrm{X}_{\mathrm{c}}: 1160 \mathrm{MPa} \mathrm{Y}_{\mathrm{t}}: 29 \mathrm{MPa} \mathrm{Y}_{\mathrm{c}}: 157.9 \mathrm{MPa} \\
\text { S: } 91 \mathrm{MPa}\end{array}$ & $\begin{array}{c}\mathrm{E}_{11}: 41.0 \mathrm{GPa}_{22}: 10.4 \mathrm{GPa}_{12}: 0.28 \mathrm{G}_{12}: 4.7 \mathrm{GPa} \\
\mathrm{X}_{\mathrm{t}}: 1140 \mathrm{MPa} \mathrm{X}_{\mathrm{c}}: 620 \mathrm{MPa} \mathrm{Y}_{\mathrm{t}}: 39 \mathrm{MPa} \mathrm{Y}_{\mathrm{c}}: 128 \mathrm{MPa} \\
\text { S: } 89 \mathrm{MPa}\end{array}$ \\
\hline
\end{tabular}

* E is Young's modulus; G is shear modulus; $v$ is Poisson's ratio; Xt and Xc are the tensile and compression strengths at fibre longitudinal direction; Yt and Yc are the tensile and compression strengths at fibre transverse direction; $\mathrm{S}$ is shear strength.

Table 3 The investigated types of straight-fibre, steered-fibre, and hybrid laminates

\begin{tabular}{|c|c|c|c|}
\hline \multirow{4}{*}{$\begin{array}{c}\text { Laminates } \\
\text { type }\end{array}$} & Straight-fibre & Steered-fibre & Hybrid laminates \\
\cline { 2 - 4 } & {$\left[(90 / 0)_{4}\right] \mathrm{s}$} & & \\
& {$\left[( \pm 45)_{4}\right] \mathrm{s}$} & & {$\left[( \pm \mathrm{SFP})_{2} /(90 / 0)_{2}\right] \mathrm{s}$} \\
& {$\left[( \pm 45)_{2} /(90 / 0)_{2}\right] \mathrm{s}$} & {$\left[( \pm \mathrm{SFP})_{4}\right] \mathrm{s}$} & {$\left[( \pm 45)_{2} /(\mathrm{SFP})_{2}\right] \mathrm{s}$} \\
& {$\left[(90 / 0)_{2} /( \pm 45)_{2}\right] \mathrm{s}$} & & \\
\hline Ply thickness & {$\left[( \pm 45)_{2} /( \pm 30) /( \pm 45) /( \pm 15)\right] \mathrm{s}$} & & \\
\hline
\end{tabular}


Table 4 Buckling resistance loads of the carbon fibre laminates in ideal equal-mass scenarios. The data show the percentage reduction in buckling load due to the introduction of a hole in the plate for each laminate.

\begin{tabular}{|c|c|c|c|}
\hline & $\begin{array}{c}\mathbf{3 0 0 m m} \times \mathbf{4 0 0} \mathbf{~ m m} \\
\text { panel (no hole) }\end{array}$ & $\begin{array}{c}\text { 300mm } \times \mathbf{4 0 0 ~} \mathbf{m m} \text { panel } \\
(\mathbf{9 0 m m} \text { diameter centre hole) }\end{array}$ & $\begin{array}{c}\text { Decrease } \\
\text { ratio }\end{array}$ \\
\hline$\left[(90 / 0)_{4}\right] \mathrm{s}$ & $5.69 \mathrm{kN}$ & $4.94 \mathrm{kN}$ & $13.18 \%$ \\
\hline$\left[( \pm 45)_{4}\right] \mathrm{s}$ & $5.51 \mathrm{kN}$ & $4.96 \mathrm{kN}$ & $9.98 \%$ \\
\hline$\left[( \pm 45)_{2} /(90 / 0)_{2}\right] \mathrm{s}$ & $6.17 \mathrm{kN}$ & $5.69 \mathrm{kN}$ & $7.78 \%$ \\
\hline$\left[(90 / 0)_{2} /( \pm 45)_{2}\right] \mathrm{s}$ & $5.60 \mathrm{kN}$ & $4.90 \mathrm{kN}$ & $12.50 \%$ \\
\hline$\left[( \pm 45)_{2} /( \pm 30) /( \pm 45) /( \pm 15)\right] \mathrm{s}$ & $5.95 \mathrm{kN}$ & $5.36 \mathrm{kN}$ & $9.92 \%$ \\
\hline$\left[( \pm \mathrm{SFP})_{4}\right] \mathrm{s}$ & $5.55 \mathrm{kN}$ & $5.33 \mathrm{kN}$ & $3.96 \%$ \\
\hline$\left[( \pm \mathrm{SFP})_{2} /(90 / 0)_{2}\right] \mathrm{s}$ & $6.51 \mathrm{kN}$ & $6.11 \mathrm{kN}$ & $6.14 \%$ \\
\hline$\left[( \pm 45)_{2} /( \pm \mathrm{SFP})_{2}\right] \mathrm{s}$ & $5.62 \mathrm{kN}$ & $5.31 \mathrm{kN}$ & $5.52 \%$ \\
\hline
\end{tabular}

Table 5 The predicted buckling resistance properties of carbon and glass fibre laminates (containing a hole) for an equal-mass scenario

\begin{tabular}{|c|c|c|c|}
\hline \multirow{2}{*}{ Carbon Fibre } & \multirow{2}{*}{$\begin{array}{l}\text { Buckling load } \\
(\mathrm{kN})\end{array}$} & \multicolumn{2}{|c|}{ Failure load (kN) } \\
\hline & & Hashin & LaRC05 \\
\hline$\left[( \pm 45)_{2} /(90 / 0)_{2}\right] \mathrm{s}$ & 5.69 & 43.60 & 28.07 \\
\hline$\left[( \pm 60)_{2} /(90 / 0)_{2}\right] \mathrm{s}$ & $6.04(+6.1 \%)$ & $42.07(-3.6 \%)$ & $26.09(-7.1 \%)$ \\
\hline$\left[( \pm S F P)_{2} /(90 / 0)_{2}\right] s$ & $6.11(+7.4 \%)$ & $45.76(+4.9 \%)$ & $29.30(+4.4 \%)$ \\
\hline \multirow{2}{*}{ Glass Fibre } & Buckling load & \multicolumn{2}{|c|}{ Failure load (kN) } \\
\hline & $(k N)$ & Hashin & LaRC05 \\
\hline$\left[( \pm 45)_{2} /(90 / 0)_{2}\right] \mathrm{s}$ & 2.28 & 15.56 & 12.61 \\
\hline$\left[( \pm 60)_{2} /(90 / 0)_{2}\right] \mathrm{s}$ & $2.38(+4.4 \%)$ & $15.23(-2.2 \%)$ & $11.86(-5.9 \%)$ \\
\hline$\left[( \pm S F P)_{2} /(90 / 0)_{2}\right] s$ & $2.41(+5.7 \%)$ & $17.05(+9.5 \%)$ & $13.84(+9.8 \%)$ \\
\hline
\end{tabular}




\section{References}

1. Abdiwi, F., Harrison, P., Koyama, I., Yu, W.R., Long, A.C., Corriea, N., and Guo, Z., Characterising and modelling variability of tow orientation in engineering fabrics and textile composites. Composites Science and Technology, 2012. 72(9): p. 1034-1041.

2. HYER, M.W. and CHARETTE, R.F., Use of curvilinear fiber format in composite structure design. AIAA Journal, 1991. 29(6): p. 1011-1015.

3. Hyer, M.W. and Lee, H.H., The use of curvilinear fiber format to improve buckling resistance of composite plates with central circular holes. Composite Structures, 1991. 18(3): p. 239-261.

4. Lozano, G.G., Tiwari, A., Turner, C., and Astwood, S., A review on design for manufacture of variable stiffness composite laminates. Proceedings of the Institution of Mechanical Engineers, Part B: Journal of Engineering Manufacture, 2016. 230(6): p. 981-992.

5. Tatting, B.F. and Gurdal, Z., Design and Manufacture of Elastically Tailored Tow Placed Plates. Tech. rep., NASA, 2002. NASA/CR-2002-211919.

6. Gürdal, Z., Tatting, B.F., and Wu, C.K., Variable stiffness composite panels: Effects of stiffness variation on the in-plane and buckling response. Composites Part A: Applied Science and Manufacturing, 2008. 39(5): p. 911-922.

7. Lopes, C.S., Camanho, P.P., Gurdal, Z., and Tatting, B.F., Progressive failure analysis of towplaced, variable-stiffness composite panels. International Journal of Solids and Structures, 2007. 44: p. 8493-8561.

8. Weaver, P.M., Potter, K.D., Hazra, K., Saverymuthapulle, M.A.R., and Hawthorne, M.T., Buckling of Variable Angle Tow Plates: from Concept to Experiment, in 50th AlAA Structures, Structural Dynamics, and Materials Conference 2009: California.

9. Lopes, C.S., Gurdal, Z., and Camanho, P.P., Variable-stiffness composite panels: Buckling and first-ply failure improvements over straight-fibre laminates. Computers and Structures, 2008. 86: p. 897-907.

10. Ijsselmuiden, S.T., Abdalla, M.M., and Gürdal, Z., Optimization of Variable-Stiffness Panels for Maximum Buckling Load Using Lamination Parameters. AIAA Journal, 2010. 48(1): p. 134-143.

11. Arian Nik, M., Fayazbakhsh, K., Pasini, D., and Lessard, L., Optimization of variable stiffness composites with embedded defects induced by Automated Fiber Placement. Composite Structures, 2014. 107: p. 160-166.

12. Marouene, A., Boukhili, R., Chen, J., and Yousefpour, A., Buckling behavior of variable-stiffness composite laminates manufactured by the tow-drop method. Composite Structures, 2016. 139: p. 243-253.

13. Hao, P., Yuan, X., Liu, H., Wang, B., Liu, C., Yang, D., and Zhan, S., Isogeometric buckling analysis of composite variable-stiffness panels. Composite Structures, 2017. 165: p. 192-208.

14. Hao, P., Wang, Y., Ma, R., Liu, H., Wang, B., and Li, G., A new reliability-based design optimization framework using isogeometric analysis. Computer Methods in Applied Mechanics and Engineering, 2019. 345: p. 476-501.

15. Hao, P., Liu, D., Wang, Y., Liu, X., Wang, B., Li, G., and Feng, S., Design of manufacturable fiber path for variable-stiffness panels based on lamination parameters. Composite Structures, 2019. 219: p. 158-169.

16. Setoodeh, S., Blom, A., Abdalla, M., and Gürdal, Z., Generating Curvilinear Fiber Paths from Lamination Parameters Distribution, in 47th AIAA/ASME/ASCE/AHS/ASC Structures, Structural Dynamics, and Materials Conference.

17. Campen, J.v. and Gürdal, Z., Retrieving Variable Stiffness Laminates from Lamination Parameters Distribution, in 50th AIAA/ASME/ASCE/AHS/ASC Structures, Structural Dynamics, and Materials Conference. 2009. 
18. Alhajahmad, A., Abdalla, M.M., and Gürdal, Z., Optimal Design of Tow-Placed Fuselage Panels for Maximum Strength with Buckling Considerations. Journal of Aircraft, 2010. 47(3): p. 775782.

19. Coburn, B.H., Wu, Z., and Weaver, P.M., Buckling analysis of stiffened variable angle tow panels. Composite Structures, 2014. 111: p. 259-270.

20. Kim, B., Hazra, K., Weaver, P., and Potter, K. Limitations of fibre placement techniques for variable angle tow composites and their process-induced defects. in 18th ICCM. 2011. Jeju, KR.

21. Kim, B.C., Potter, K., and Weaver, P.M., Continuous tow shearing for manufacturing variable angle tow composites. Composites Part A: Applied Science and Manufacturing, 2012. 43(8): p. 1347-1356.

22. Kim, B.C., Weaver, P.M., and Potter, K., Manufacturing characteristics of the continuous tow shearing method for manufacturing of variable angle tow composites. Composites Part A: Applied Science and Manufacturing, 2014. 61: p. 141-151.

23. Wu, K., Tatting, B., Smith, B., Stevens, R., Occhipinti, G., Swift, J., Achary, D., and Thornburgh, R., Design and Manufacturing of Tow-Steered Composite Shells Using Fiber Placement, in 50th AIAA/ASME/ASCE/AHS/ASC Structures, Structural Dynamics, and Materials Conference. 2009, American Institute of Aeronautics and Astronautics.

24. Falcó, O., Mayugo, J.A., Lopes, C.S., Gascons, N., Turon, A., and Costa, J., Variable-stiffness composite panels: As-manufactured modeling and its influence on the failure behavior. Composites Part B: Engineering, 2014. 56: p. 660-669.

25. Falcó, O., Lopes, C.S., Naya, F., Sket, F., Maimí, P., and Mayugo, J.A., Modelling and simulation of tow-drop effects arising from the manufacturing of steered-fibre composites. Composites Part A: Applied Science and Manufacturing, 2017. 93: p. 59-71.

26. Marouene, A., Boukhili, R., Chen, J., and Yousefpour, A., Effects of gaps and overlaps on the buckling behavior of an optimally designed variable-stiffness composite laminates - A numerical and experimental study. Composite Structures, 2016. 140: p. 556-566.

27. Xiao, Z. and Harrison, P., Buckling Analysis of Variable Stiffness Panels Manufactured by Fabric Steering Technology, in 22nd International Conference on Composites Materials (ICCM22). 2019: Melbourne, Australia.

28. ABAQUS, Abaqus 2017 User's Manual. 2017: USA.

29. Long, A.C., Wiggers, J., and Harrison, P., Modelling the Effects of Blank-Holder Pressure and Material Variability on Forming of Textile Preforms, in 8th Int. ESAFORM Conf. on Materials Forming. 2004: Cluj-Napoca, Romania.

30. Harrison, P., Janssen, L.J.P., Navez, V.P., Peters, G.W.M., and Baaijens, F.P.T., Birefringence measurements on polymer melts in an axisymmetric flow cell. Rheologica Acta, 2002. 41(1): p. 114-133.

31. Harrison, P., Taylor, E., and Alsayednoor, J., Improving the accuracy of the uniaxial bias extension test on engineering fabrics using a simple wrinkle mitigation technique. Composites Part A: Applied Science and Manufacturing, 2018. 108: p. 53-61.

32. Kim, B.C., Weaver, P.M., and Potter, K., Computer aided modelling of variable angle tow composites manufactured by continuous tow shearing. Composite Structures, 2015. 129: p. 256-267.

33. Daniel, I.M. and Ishai, O., Engineering mechanics of composite materials (2nd edition). 2006: Oxford university press

34. Riks, E., An incremental approach to the solution of snapping and buckling problems. International Journal of Solids and Structures, 1979. 15(7): p. 529-551.

35. ABAQUS. Abaqus Analysis User's Guide - 6.2.4 Unstable collapse and postbuckling analysis. April 2020]; Available from: http://ivtabaqusdoc.ivt.ntnu.no:2080/v6.14/books/usb/default.htm.

36. Hashin, Z., Failure criteria for unidirectional fibre composites. Journal of Applied Mechanics, 1980. 47: p. 329-334. 
37. Pinho, S.T., Darvizeh, R., Robinson, P., Schuecker, C., and Camanho, P.P., Material and structural response of polymer-matrix fibre-reinforced composites. Journal of Composite Materials, 2012. 46: p. 2313-2341.

38. Pinho, S., Vyas, G., and Robinson, P., Material and structural response of polymer-matrix fibrereinforced composites: Part B. Journal of Composite Materials, 2013. 47(6-7): p. 679-696.

39. Pinho, S.T., Dávila, C.G., Camanho, P.P., lannucci, L., and Robinson, P., Failure models and criteria for FRP under in-plane or three-dimensional stress states including shear non-linearity. 2005. 